\title{
Characterizing the North American Monsoon in the Community Atmosphere Model: Sensitivity to Resolution and Topography
}

\author{
ARIANNA M. VARUOLO-CLARKE \\ School of Marine and Atmospheric Sciences, Stony Brook University, State University of New York, Stony Brook, and Lamont-Doherty \\ Earth Observatory, and Department of Earth and Environmental Sciences, Columbia University, New York, New York \\ KEVIN A. REED \\ School of Marine and Atmospheric Sciences, Stony Brook University, State University of New York, Stony Brook, New York \\ BRIAN MEDEIROS \\ National Center for Atmospheric Research, Boulder, Colorado
}

(Manuscript received 29 August 2018, in final form 25 August 2019)

\begin{abstract}
This work examines the effect of horizontal resolution and topography on the North American monsoon (NAM) in experiments with an atmospheric general circulation model. Observations are used to evaluate the fidelity of the representation of the monsoon in simulations from the Community Atmosphere Model version 5 (CAM5) with a standard $1.0^{\circ}$ grid spacing and a high-resolution $0.25^{\circ}$ grid spacing. The simulated monsoon has some realistic features, but both configurations also show precipitation biases. The default $1.0^{\circ}$ grid spacing configuration simulates a monsoon with an annual cycle and intensity of precipitation within the observational range, but the monsoon begins and ends too gradually and does not reach far enough north. This study shows that the improved representation of topography in the high-resolution $\left(0.25^{\circ}\right.$ grid spacing $)$ configuration improves the regional circulation and therefore some aspects of the simulated monsoon compared to the $1.0^{\circ}$ counterpart. At higher resolution, CAM5 simulates a stronger low pressure center over the American Southwest, with more realistic low-level wind flow than in the $1.0^{\circ}$ configuration. As a result, the monsoon precipitation increases as does the amplitude of the annual cycle of precipitation. A moisture analysis sheds light on the monsoon dynamics, indicating that changes in the advection of enthalpy and moist static energy drive the differences between monsoon precipitation in CAM5 $1.0^{\circ}$ compared to the $0.25^{\circ}$ configuration. Additional simulations confirm that these improvements are mainly due to the topographic influence on the low-level flow through the Gulf of California, and not only the increase in horizontal resolution.
\end{abstract}

\section{Introduction}

The southwest United States and northwestern Mexico experience a monsoon circulation that dominates the annual cycle of precipitation associated with alternating dry and wet seasons, known as the North American monsoon (NAM; Adams and Comrie 1997). The peak monsoon season is from July through September (JAS) with the strongest monsoon precipitation occurring in northwestern Mexico over the western foothills of the Sierra Madre Occidental Mountains with a weakening

Corresponding author: Arianna M. Varuolo-Clarke, ariannav@ ldeo.columbia.edu signal through the southwestern United States (i.e., Arizona, New Mexico, and Nevada; Adams and Comrie 1997). Current understanding of the NAM and how it might respond to climate change is limited by an apparent lack of skill in current climate models (i.e., Kim et al. 2008; Gutzler et al. 2009; Castro et al. 2012; Cook and Seager 2013; Geil et al. 2013; Pascale et al. 2017); part of the deficiency is thought to be associated with inadequate horizontal resolution in today's climate models (Pascale et al. 2017). The purpose of this work is to test one climate model's ability to simulate the NAM at different horizontal resolutions.

The development of the thermal low pressure center over the Colorado River Valley results in a pressure 
gradient that draws moisture northward through the Gulf of California (GoC; Adams and Comrie 1997). This increased moisture leads to instability and enhanced convection over the mountains and deserts in the southwestern United States and northwestern Mexico. The climatological onset of the NAM has been correlated with a positive land-sea thermal contrast (Turrent and Cavazos 2009), with wetter monsoons being characterized by stronger land-sea thermal contrast than drier monsoons. The summertime precipitation in the NAM region is also dictated by the location of an upperlevel anticyclone (Reed 1933). When the anticyclone is east of the Rocky Mountains moisture reaches farther north, while moisture remains farther south when the anticyclone is west of the Rocky Mountains. Further understanding of the NAM dynamics can be found in studies by Reed (1933), Bryson and Lowry (1955), Carleton (1986, 1987), and Adams and Comrie (1997).

The GoC contributes most moisture to the NAM with the greatest amounts of moisture found near the entrance of the GoC below $850 \mathrm{hPa}$ (Turrent and Cavazos 2009) and in the northern GoC, when the flow is approximately parallel to the axis of the gulf. This lowlevel flow is a result of the low-level jet that develops during the summer months (Douglas 1995). There are also moisture surges through the GoC that provide synoptic-scale forcing to support mesoscale convective systems (Adams and Stensrud 2007; Newman and Johnson 2013; Seastrand et al. 2015; Pascale et al. 2018). Moisture from the Gulf of Mexico (GoM) also contributes to the NAM region but mostly through upperlevel moisture transport (Reitan 1957; Rasmusson 1967; Schmitz and Mullen 1996; Adams and Comrie 1997; Anderson and Roads 2001; Dominguez et al. 2016).

The geography and topography of the NAM region influence the development and maintenance of the monsoon. The region is bounded by the Pacific Ocean and the GoC to the west where sea surface temperatures (SSTs) along the Pacific Coast remain cool $\left(<25^{\circ} \mathrm{C}\right)$ during summer, with warmer temperatures in the GoC and tropical eastern Pacific $\left(>28^{\circ} \mathrm{C}\right)$. To the east, the NAM region is bounded by the Sierra Madre Occidental and in the far east by the warm GoM $\left(>26^{\circ} \mathrm{C}\right)$, and by the central Plains of the United States (Adams and Comrie 1997). The Peninsular Ranges of southern California, Baja California, and Baja California Sur limit moisture from entering the NAM region from the eastern Pacific. The summer daytime heating in lowlands and elevated areas is crucial in the development of the thermal low and subsequent convection. The thermal low and associated overturning circulation (Trenberth et al. 2000) encourage moisture fluxes into the NAM region, defining the monsoon such that the western United States and northern Mexico plateau promote a monsoonal circulation pattern comparable to the influence the Tibetan Plateau has on the monsoonal circulation over East Asia (Tang and Reiter 1984; Reiter and Tang 1984).

Several studies have investigated the influence of resolution and topography on the NAM in weather forecast models as well as regional- and global-scale climate models. Tripathi and Dominguez (2013) examined the effects of spatial resolution on the ability of regional climate models to capture observed extreme precipitation in the southwest United States. Analyzing two simulations, of $10-$ and $50-\mathrm{km}$ resolutions, over 1980-2010, the authors found that the mean climatological spatial structure of the southwest U.S. precipitation was well represented at the higher resolution but not at the lower resolution. Despite a larger positive bias in mean summer precipitation, the $10-\mathrm{km}$ resolution simulation also captured individual extreme summer precipitation events better than the $50-\mathrm{km}$ simulation. In another study by Castro et al. (2012), the authors found that higher-resolution regional climate models better simulate monsoon precipitation compared to lowerresolution global climate models. The authors refer to poor representation of terrain forcing, mesoscale features (e.g., low-level jets), land-atmosphere coupling, and parameterized convective rainfall in global models as reasons for the poor simulation of monsoon precipitation. Gutzler et al. (2009) examined the NAM precipitation in six global and four regional models that were all forced with prescribed and time-varying SSTs. Those authors found that the variability of precipitation in Arizona and New Mexico is simulated better in regional models when compared with global models (including an earlier version of the National Center for Atmospheric Research Community Atmosphere Model used in the present study). These results highlight the importance of transient circulation anomalies, which are prescribed as lateral boundary conditions in the regional models, in simulating the northern reaches of the monsoon precipitation.

Cook and Seager (2013) investigated simulations from phase 5 of the Coupled Model Intercomparison Project (CMIP5) to examine how the NAM will respond to increased greenhouse gas concentrations in general circulation models (GCMs). Results suggest no change in the total NAM rainfall, but a shift in the seasonal distribution of precipitation in future simulations (Cook and Seager 2013). However, many current generation GCMs with horizontal grid spacing coarser than $100 \mathrm{~km}$, which is the majority of models participating in phases 3 and 5 of CMIP, are unable to realistically resolve the topography in the NAM region, which can have negative 
consequences on the simulation of the NAM (Geil et al. 2013). At this coarse resolution, the GoC summertime low-level flow is not well resolved, which inhibits an accurate representation of precipitation over parts of the American Southwest (Kim et al. 2008; Pascale et al. 2017), limiting our understanding of processes and mechanisms important to the NAM. Using a GCM with a higher horizontal resolution of $50-\mathrm{km}$ grid spacing, Pascale et al. (2017) found a robust reduction in monsoonal precipitation to doubled $\mathrm{CO}_{2}$ concentrations in the American Southwest.

Building on previous studies of the influence of horizontal resolution and topography on the simulation of the NAM (Gutzler et al. 2009; Castro et al. 2012; Tripathi and Dominguez 2013), this research seeks to bridge the gap between some of the most recent GCM assessments (i.e., Cook and Seager 2013; Pascale et al. 2017) that have highlighted the uncertainty in projections of the NAM in state-of-the-art climate models, and emphasize how simulating the NAM depends on accurate representation of topographic features. Better understanding this uncertainty will allow for the development of more credible climate projections; these projections are crucial for this region as water resources are scarce and have many societal and ecological consequences. Using simulations from the Community Atmosphere Model version 5 (CAM5), a free running atmospheric GCM at horizontal resolutions of approximately 100 and $25 \mathrm{~km}$, we seek to assess the simulation of the NAM and characterize the sensitivity to resolution and subsequent sensitivity to orographic forcing on NAM precipitation in this model. By analyzing GCMs, we can investigate problems that are global in scope and simulate the large-scale circulation that influences the monsoon. The following research questions are addressed:

1) Does CAM5 simulate a realistic monsoon compared to observations, in terms of magnitude and timing? (section 3)

2) Does increased horizontal resolution in CAM5 improve the representation of the NAM? (section 4)

3) Can we quantify the differences in the representation of the NAM at these two horizontal resolutions by isolating the orographic contribution? (section 5)

\section{Data and methodology}

\section{a. Community Atmosphere Model}

We evaluate the NAM and the role of horizontal resolution using version 5 of the Community Atmosphere Model (CAM5; Neale et al. 2012). These simulations use the finite-volume dynamical core on a latitude-longitude grid and are configured as described in Wehner et al. (2014). All simulations have 30 vertical levels with an uppermost model level (i.e., model top) of $2 \mathrm{hPa}$ (Richter et al. 2014). The model is forced using prescribed monthly SSTs, sea ice extent, and greenhouse gas forcing following the Atmospheric Model Intercomparison Project (AMIP) protocols (Gates et al. 1999). The northern GoC is handled by the land model; even though SST is prescribed, the "wetland" categorization of the northern GoC allows a predicted surface temperature that is similar to a slab ocean model. The analysis period is 1980-2005; one year (1979) is discarded to allow the model, especially the land surface, to spin up (Wehner et al. 2014).

We start by analyzing a simulation of CAM5 on a $0.9^{\circ} \times 1.25^{\circ}$ mesh (referred to as $1.0^{\circ}$ ) to test the simulation of NAM at the standard horizontal resolution. To test the simulated NAM at a higher horizontal resolution, we investigate a CAM5 configuration with a horizontal resolution of $0.23^{\circ} \times 0.31^{\circ}$ (referred to as $0.25^{\circ}$ ). At the $0.25^{\circ}$ horizontal resolution, Wehner et al. (2014) showed improvements in extreme precipitation. Bacmeister et al. (2014) found that while the $0.25^{\circ}$ experiments of CAM, versions 4 and 5, simulate a climate similar to the $1.0^{\circ}$ simulation, there are improvements where topography influences circulation. For example, the simulation of the Indian summer monsoon in CAM4 was improved at the $0.25^{\circ}$ horizontal resolution.

Using the $0.25^{\circ}$ simulation conflates the effects of better resolving smaller scales with the impact of topography. Disentangling the two, however, is challenging. As a step toward isolating the impact of topography we have conducted a small ensemble of simulations with the CAM5 $0.25^{\circ}$ configuration in which everything remains the same as the AMIP simulations except that the topography is taken from the $1.0^{\circ}$ configuration and regridded to the $0.25^{\circ}$ grid; the ensemble members differ only in their initial condition (see the appendix for details). Longer simulations could not be conducted due to limited computational resources, but this initial work provides sufficient evidence for the present study and serves as a foundation for future studies to better address the distinction between circulation and topographic effects.

In terms of data volume, it is noteworthy that a single latitude-longitude field, like surface pressure, is represented in the $1.0^{\circ}$ model output by a $192 \times 288$ grid of 32 bit values $(221 \mathrm{MB})$ per time sample while the $0.25^{\circ}$ model has a $768 \times 1152$ grid $(3.5 \mathrm{~GB})$-a 16 -fold increase in size. For numerical stability, the time step must also be decreased at higher spatial resolution, so the computational cost of the $0.25^{\circ}$ model is about $32(=4 \times$ $4 \times 2$ ) times that of the $1.0^{\circ}$ model. The purpose of this 
work is to understand if the improvements in topography at the $0.25^{\circ}$ horizontal resolution result in an improved representation of the NAM circulation. This gives the community further reason to perform such experiments in the future to better understand how well CAM5 can be used to understand how climate change will impact the NAM, justifying the increase in computing costs, and inform future studies of the benefit of the additional computational burden.

Figure 1 shows the elevation of topography for Modern-Era Retrospective Analysis for Research and Applications version 2 (MERRA-2; Gelaro et al. 2017) and the $1.0^{\circ}$ and $0.25^{\circ} \mathrm{CAM} 5$ simulations over the NAM region. As expected, the $0.25^{\circ}$ topography presents much more detail and higher peak elevation than the smoother $1.0^{\circ}$ topography. In particular, the Baja California Peninsula has little or no elevation in the $1.0^{\circ}$ simulation, which is improved to have more realistic topographic features at the $0.25^{\circ}$ horizontal resolution. Whereas the $1.0^{\circ}$ configuration blurs the differentiation of the $\mathrm{GoC}$, the $0.25^{\circ}$ configuration definitively separates the GoC from the eastern Pacific, both in terms of SST and with the topographic barrier provided by the Baja California Peninsula. Figure 1 also shows the outline of the land-sea mask for each model, and through this presentation, land makes up most of the GoC in the $1.0^{\circ}$ simulation compared to the $0.25^{\circ}$ model. However, recall that the northern GoC is handled as wetland, so the coastline shown is slightly misleading as there are a few more grid points that are effectively ocean. We hypothesize that these differences in topography drive differences between the simulated monsoon at each of these horizontal resolutions in CAM5, where more realistic local circulation and moisture transport over the $\mathrm{GoC}$ at the higher resolution $\left(0.25^{\circ}\right)$ will simulate a more realistic monsoon. Since the GoC is the primary lowlevel moisture source for the monsoon, the absence of topography over Baja California in the $1.0^{\circ}$ simulation is expected to negatively affect the representation of the monsoon circulation (Adams and Comrie 1997). These differences in topography between the $1.0^{\circ}$ and the $0.25^{\circ}$ configurations allow an examination of the effect of horizontal resolution on the monsoon circulation. Monthly means are used for analysis of precipitation, sea level pressure, winds, and vertical pressure velocity. The moisture calculations detailed below are performed using daily means.

\section{b. Observations and reanalysis}

Data from satellite-borne passive and active sensors from the Tropical Rainfall Measuring Mission (TRMM; 3B43: Multisatellite Precipitation; Kummerow et al. 1998) are used for observations of precipitation for the
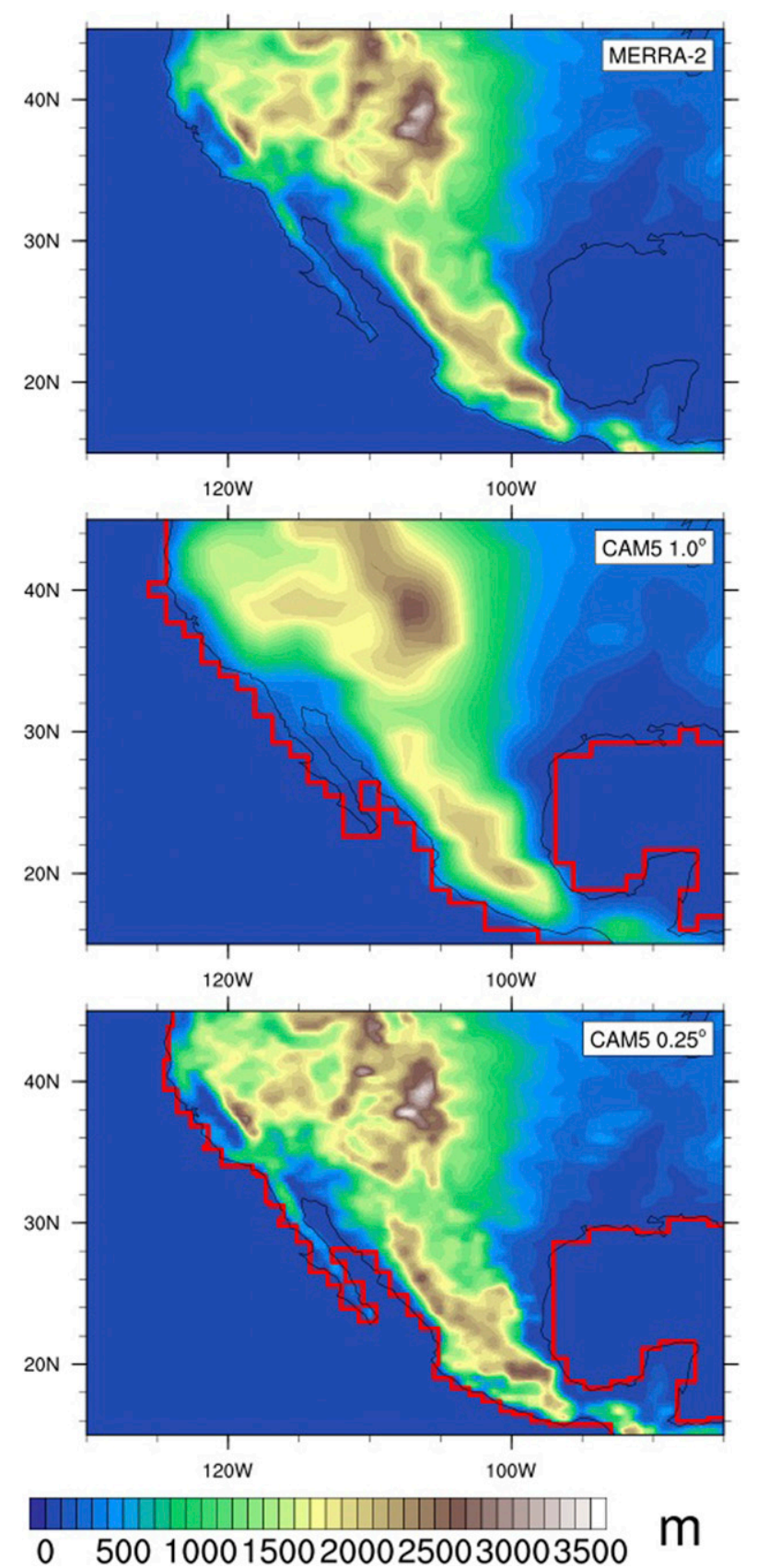

FIG. 1. Topography field (m) in MERRA-2, CAM5 $1.0^{\circ}$, and CAM5 $0.25^{\circ}$. The coastline for the CAM5 simulations is shown as the red line.

1998-2005 time period. This analysis uses precipitation from TRMM 3B43 provided at monthly temporal resolution on a $0.25^{\circ} \times 0.25^{\circ}$ grid. Additionally, a combined observational product based on satellite and rain gauge measurements from the Global Precipitation Climatology Project (GPCP; Huffman et al. 2009) is used at a $2.5^{\circ}$ spatial resolution, spanning from 1980 to 2005, also at a monthly temporal resolution. It should be noted these 
two precipitation datasets are not independent as they both use the GPCP rain gauge analysis, but while the GPCP dataset is a blending of the rain gauge analysis with satellite data, those data do not include TRMM (cf. Adler et al. 2018). Meteorological variables-including wind, sea level pressure, and thermodynamic variablesare obtained from MERRA-2 (Gelaro et al. 2017; Global Modeling and Assimilation Office 2015a,b,c,d) for the time period of 1980-2005 at a spatial resolution of $0.5^{\circ} \times 0.667^{\circ}$ at both daily and monthly temporal resolutions.

\section{c. Moisture budget}

The moist static energy $\left(h=c_{p} T+g z+L_{v} q\right)$ is an approximation of the atmospheric enthalpy and is nearly conserved under hydrostatic and adiabatic thermodynamic transformations (see, e.g., Neelin 2007; Yano and Ambaum 2017). With the usual approximations, $h$ is also conserved for thermodynamic transformations including precipitation, although this approximation neglects to account for the ice phase (and is not conserved under freezing/melting/sublimation). The moisture analysis performed here is similar to that of Chen and Bordoni (2014) for the East Asian summer monsoon, using the vertically integrated moist static energy (MSE) budget. The advantage of the vertically integrated MSE budget is that it provides a convenient comparison of contributions from radiation, turbulent fluxes, and transport processes to the moist dynamics of the NAM (see also Chou and Neelin 2003; Neelin 2007).

The vertically integrated MSE is derived by vertically integrating [where $\langle\cdot\rangle=\int(\cdot) d p / g$ ] and combining the thermodynamic and moisture equations, respectively:

$$
c_{p}\left\langle\partial_{t} T\right\rangle+c_{p}\langle v \cdot \nabla T\rangle+\left\langle\omega \partial_{p} s\right\rangle=\left\langle Q_{c}\right\rangle+S^{\text {net }}+R^{\text {net }}+\mathrm{SH},
$$

$$
\left\langle\partial_{t} q\right\rangle+\langle v \cdot \nabla q\rangle+\left\langle\omega \partial_{p} q\right\rangle=L_{v}^{-1}(\mathrm{LH}-P)
$$

where $c_{p}$ is the specific heat at constant pressure, $T$ is temperature, $v$ is the horizontal wind, $\omega$ is the vertical pressure velocity, and $s=c_{p} T+g z$ is the dry static energy, such that $g$ is gravitational acceleration and $z$ is geopotential height. Energy fluxes are denoted by $Q_{c}$, which is the convective heating; $S^{\text {net }}$ and $R^{\text {net }}$ are the net shortwave and net longwave radiation, respectively; and $\mathrm{SH}$ and $\mathrm{LH}$ are the, sensible and latent surface heat fluxes, respectively. Latent heat of vaporization is denoted as $L_{v}, q$ is the specific humidity, and $P$ is precipitation. Changes in time or pressure are indicated by $\partial_{t}$ and $\partial_{p}$, respectively. Summing Eqs. (1) and (2) and averaging over a climatological period [denoted by $\overline{(\cdot)}$ ], the MSE balance can be simplified as an enthalpy budget:

$$
\left\langle\overline{\frac{\partial E}{\partial t}}\right\rangle=\overline{F^{\mathrm{net}}}-\langle\overline{v \cdot \nabla E}\rangle-\left\langle\overline{\omega \frac{\partial h}{\partial p}}\right\rangle,
$$

such that

$$
F^{\text {net }}=S_{t}^{\downarrow}-S_{t}^{\uparrow}-S_{s}^{\downarrow}+S_{s}^{\uparrow}-R_{t}^{\uparrow}+R_{s}^{\uparrow}-R_{s}^{\downarrow}+\mathrm{SH}+\mathrm{LH},
$$

where $E=c_{p} T+L_{v} q$ is the atmospheric moist enthalpy, which is the sum of thermal and latent energy of the atmosphere. The flux of energy into the atmospheric column, $\overline{F^{\text {net }}}$, is a function of surface and top of the atmosphere fluxes, represented by the subscripts $t$ and $s$, respectively with $\uparrow$ indicating upward flux and $\downarrow$ being the downward flux of the shortwave radiation $S$ and longwave radiation $R$ (Chen and Bordoni 2014). The horizontal advection of moist enthalpy is denoted by $\langle\overline{v \cdot \nabla E}\rangle$. Similar to $E, h$ accounts for the movement of water vapor and temperature but also accounts for gravitational potential energy; the vertical advection of $h$ is denoted as $\overline{\langle\omega(\partial h / \partial p)\rangle}$. The vertical advection of $h$ is the product of vertical pressure velocity $\omega$ and the MSE stratification. The vertical integral of MSE stratification is negative in pressure coordinates through the troposphere and therefore regions of $\overline{\langle\omega(\partial h / \partial p)\rangle}>0$ qualitatively correspond to ascending vertical motion. Alternatively $\overline{\langle\omega(\partial h / \partial p)\rangle}<0$ corresponds to descending vertical motion (Chen and Bordoni 2014). The MSE and moisture budgets for the NAM are computed using daily averages from MERRA-2 and CAM5.

\section{Simulated monsoon}

To begin, we establish the fidelity of the NAM as represented by the standard, $1.0^{\circ} \mathrm{CAM} 5$ configuration. The NAM precipitation climatology is shown in Fig. 2, averaged over the core monsoon region $\left(112^{\circ}-102^{\circ} \mathrm{W}\right.$, $20^{\circ}-33^{\circ} \mathrm{N}$; see Fig. 3 for outline of the NAM region), similar to the region considered by Cook and Seager (2013). The black lines are the observations from TRMM (solid) and GPCP (dashed). The CAM5 1.0 simulation is shown by the solid blue line. August is the rainiest month on average for both observations and the $1.0^{\circ}$ simulation. Both observations have a minimum in precipitation occurring in April, with a large increase in precipitation occurring in June indicating the beginning of the NAM season. The $1.0^{\circ}$ configuration of CAM5 realizes a minimum in precipitation occurring in February and March, followed by a gradual increase in precipitation until June, at which time the onset of NAM 


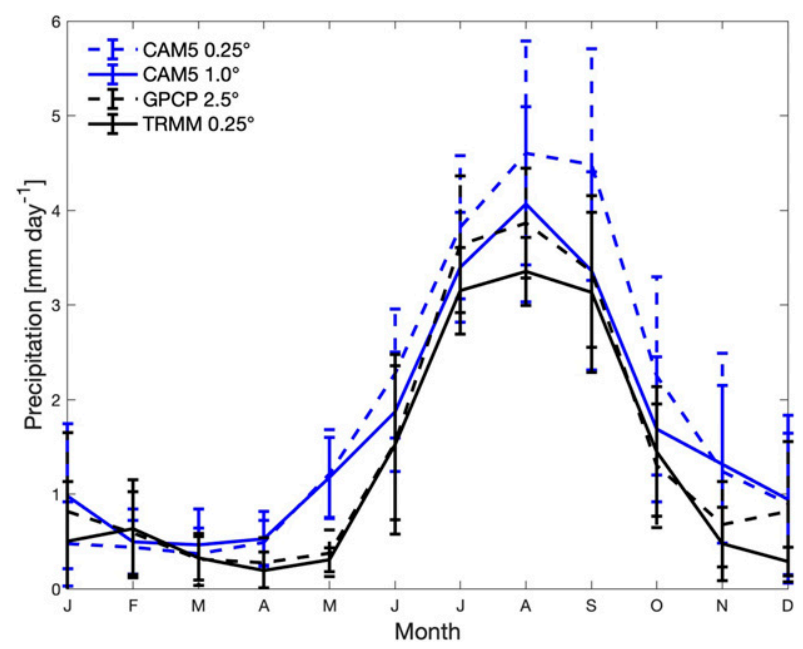

FIG. 2. Monthly precipitation climatology for TRMM (solid black) and GPCP (dashed black) compared to CAM5 $1.0^{\circ}$ (solid blue) and $0.25^{\circ}$ (dashed blue). TRMM data are plotted for 1998 2005, and the rest of the datasets include a full 26-yr climatology for 1980-2005. Vertical lines represent one standard deviation in monthly precipitation variability.

precipitation occurs in the observations. The demise of the monsoon occurs in September and October in observations, and is captured by the $1.0^{\circ}$ simulation. Overall, the $1.0^{\circ} \mathrm{CAM} 5$ configuration simulates an annual cycle of precipitation that captures the peak and demise of the monsoon within the observational range, but onset is too early and too gradual, total precipitation is too large, and monsoon withdrawal is too slow (Fig. 2); these results are comparable to those of previous studies (e.g., Cook and Seager 2013; Geil et al. 2013). Figure 2 also includes the standard deviation of precipitation to represent the interannual variability in which the $1.0^{\circ}$ simulation sees the greatest variability in September, toward the end of the monsoon. This late season variability is typically attributed to tropical cyclones (e.g., Ritchie et al. 2011). Both observations also show high amounts of variability occurring during the monsoon season.

The spatial pattern of the monsoon precipitation can be seen in Fig. 3, which is the JAS average of precipitation for TRMM, GPCP, and CAM5 with circulation parameters also included. The high-resolution TRMM product shows enhanced values of precipitation along the west coast of Mexico, concentrated along the western foothills of the Sierra Madre Occidental Mountains. At a coarser resolution, GPCP captures the essence of the monsoon with enhanced values of precipitation along the Sierra Madre Occidental Mountains, but the maximum in precipitation is lower
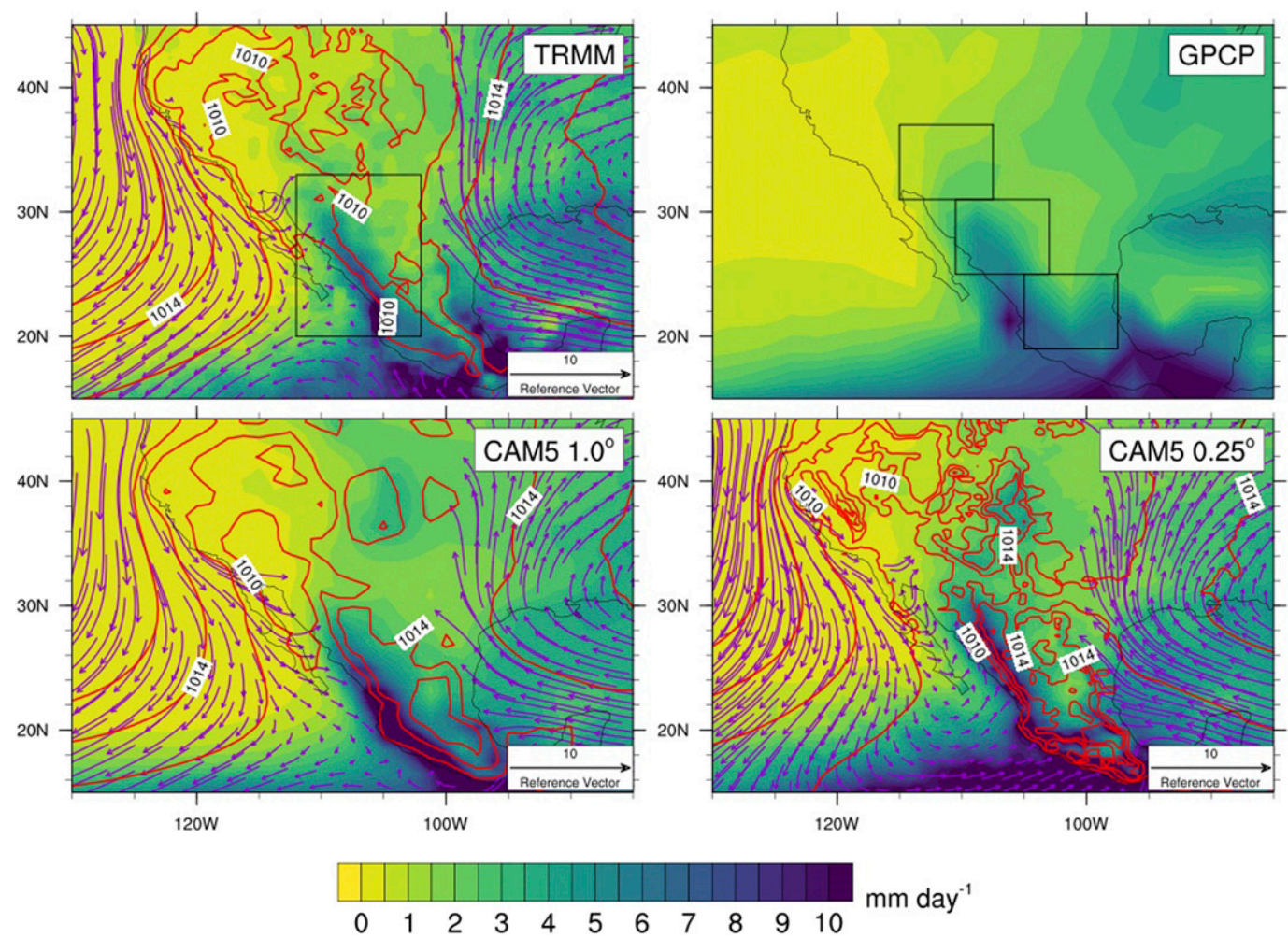

FIG. 3. NAM precipitation $\left(\mathrm{mm} \mathrm{day}^{-1}\right.$ ) averaged over the monsoon season (JAS) for TRMM, GPCP, and the $1.0^{\circ}$ and $0.25^{\circ}$ CAM5 simulations. Sea level pressure (red; hPa) and $925-\mathrm{hPa}$ wind (purple; $\mathrm{m} \mathrm{s}^{-1}$, from MERRA-2 over TRMM) are also shown. The sea level pressure is contoured from 1010 to $1016 \mathrm{hPa}$ by $2 \mathrm{hPa}$. 
than that of TRMM. The $1.0^{\circ}$ CAM5 configuration simulates a precipitation pattern that falls within the observational range of TRMM and GPCP. While the total amount of monsoon precipitation and spatial extent of precipitation along the coast are captured, the northern extension of the monsoon is not represented at $1.0^{\circ}$.

Sea level pressure and low-level winds $(925 \mathrm{hPa})$ are also shown for the same time period of 1980-2005 during the monsoon season (Fig. 3). The data contoured over TRMM precipitation are from MERRA-2. There is a weak low pressure center that develops over the northern edge of the GoC; as a result, a weak pressure gradient develops such that winds during JAS shift and are out of the west-southwest throughout most of the GoC in MERRA-2 (Fig. 3). In the $1.0^{\circ}$ configuration, however, the low that develops is not as strong as in MERRA-2 and as a result there is a less robust shift in winds during the monsoon season compared to MERRA-2, with northwesterly winds through most of the $\mathrm{GoC}$ at $925 \mathrm{hPa}$.

To better understand and quantify the spatial extent and progression of the monsoon, we analyze the annual cycle of precipitation divided into three NAM subregions [Fig. 4; as in Higgins et al. (1999)]. The northernmost region is the Arizona and New Mexico $(\mathrm{AZNM})$ region averaged over $252.5^{\circ}-245^{\circ} \mathrm{E}, 31^{\circ}-37^{\circ} \mathrm{N}$; the northwestern Mexico (NWM) region is $249.5^{\circ}-$ $257^{\circ} \mathrm{E}, 25^{\circ}-31^{\circ} \mathrm{N}$; and the southernmost region is over southwestern Mexico (SWM), $255^{\circ}-262.5^{\circ} \mathrm{E}, 19^{\circ}-25^{\circ} \mathrm{N}$ (regions are shown in Fig. 3).

In the northernmost region, AZNM, there are two peaks in precipitation observed in TRMM and GPCP: the primary monsoon peak in August and a secondary peak in February. TRMM shows a minimum in precipitation in May, with GPCP having a minimum in June. The observed peak monsoon precipitation is roughly $1.6 \mathrm{~mm} \mathrm{day}^{-1}$. The CAM5 $1.0^{\circ}$ simulation exhibits a weak annual cycle of precipitation in the AZNM region (Fig. 4) with maxima in March and August that are both near $1.0 \mathrm{~mm} \mathrm{day}^{-1}$, less than the observed peak. This result supports the climatological spatial extent of NAM precipitation in Fig. 3.

Over the NWM region, the annual cycle is similar to the core monsoon region, with one peak in precipitation. However, in the core monsoon region, precipitation peaks in August, while the peak in NWM is in July for observations from TRMM and GPCP. The peak in precipitation realized by the CAM5 $1.0^{\circ}$ simulation occurs in August, coincident with the peak of the whole core monsoon region.

Over the SWM region, TRMM and GPCP show two peaks in precipitation in July and in September. The
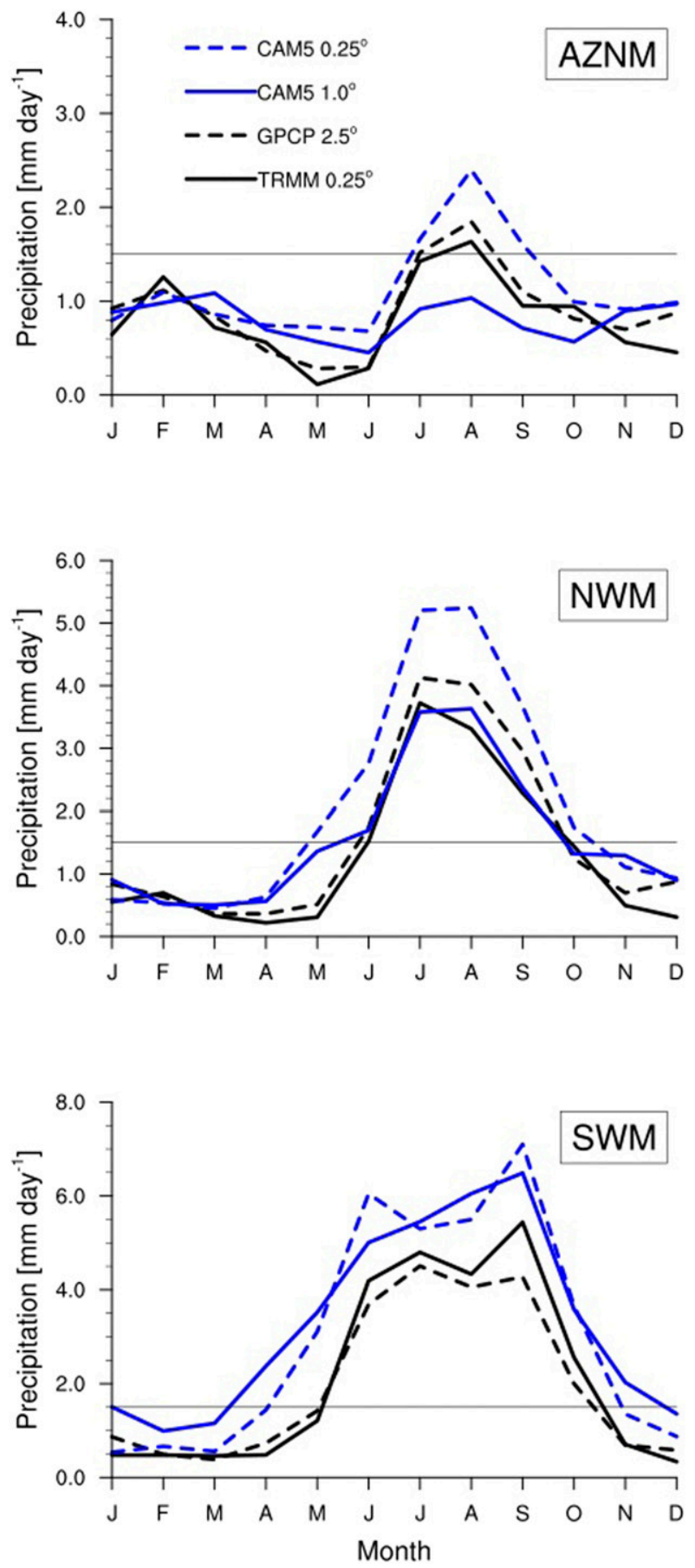

FIG. 4. Monthly precipitation climatology for TRMM (solid line), GPCP (dashed line), CAM5 1.0 (solid blue), and CAM5 $0.25^{\circ}$ (dashed blue) for 1998-2005 in TRMM and 1980-2005 in GPCP and the CAM5 simulations. Gray reference line is at $1.5 \mathrm{~mm}$ day $^{-1}$.

later peak is associated with tropical cyclones; this region is the second most affected by hurricane landfalls (after Baja California Sur) in the Pacific basin (e.g., Ritchie et al. 2011; Martinez-Sanchez and Cavazos 
2014). The CAM5 $1.0^{\circ}$ simulates one peak in precipitation during September and overestimates total rainfall in this region. The reason for the model's overestimation of precipitation at the southern edge of the monsoon region is likely a result of the ITCZ bias in CAM5 (Bacmeister et al. 2014). We speculate that this overestimation of precipitation in the SWM region balances the underestimated precipitation amounts in the AZNM region, which is why the annual cycle over the core monsoon region compares well with observations.

The ratio of monsoon season (JAS) precipitation to the annual precipitation, known as the monsoon index (MI), is shown in Fig. 5. In the observations from TRMM, the highest MI values are localized along the west coast of Mexico. The highest MI values are also localized along the west coast of Mexico parallel to the GoC in GPCP, but the spatial extent of MI values in the range of $0.7-0.8$ is less than that of TRMM. Figure 5 reiterates the conclusion that the $1.0^{\circ}$ configuration of CAM5 produces a credible NAM.

\section{Effect of horizontal resolution on the simulated monsoon}

In section 3, we discovered that CAM5 $1.0^{\circ}$ simulates some important aspects of the NAM circulation, but misses detailed aspects such as the northward extent and timing of precipitation. This section highlights results from our investigation of the simulated NAM at higher horizontal resolution $\left(0.25^{\circ}\right)$ where topography is more realistic (Fig. 1). Our hypothesis is that at the higher horizontal resolution the Baja California Peninsula provides a barrier that allows both the distinct thermal contrast between the GoC and the eastern Pacific and the potential for the lower-level flow to be channeled through the $\mathrm{GoC}$ that both provide essential ingredients for an improved NAM representation that are lacking at current generation GCM resolution. The increase in resolution primarily allows this more realistic regionalscale flow, but additionally provides a lifting mechanism as transients encounter more realistic topography as discussed in previous literature (e.g., Finch and Johnson 2010; Newman and Johnson 2012; Castro et al. 2012).

Figures 3 and 5 show that the $0.25^{\circ}$ configuration also simulates the core monsoon precipitation over northwestern Mexico, but the monsoon rains extend farther north than the $1.0^{\circ}$ simulation, more in line with observations. Averaged over the core monsoon region (Fig. 2), the $0.25^{\circ}$ simulation (dashed blue line) represents a similar annual cycle of the NAM compared to the $1.0^{\circ}$ simulation, but the total precipitation in the $0.25^{\circ}$ configuration is larger than the $1.0^{\circ}$ configuration

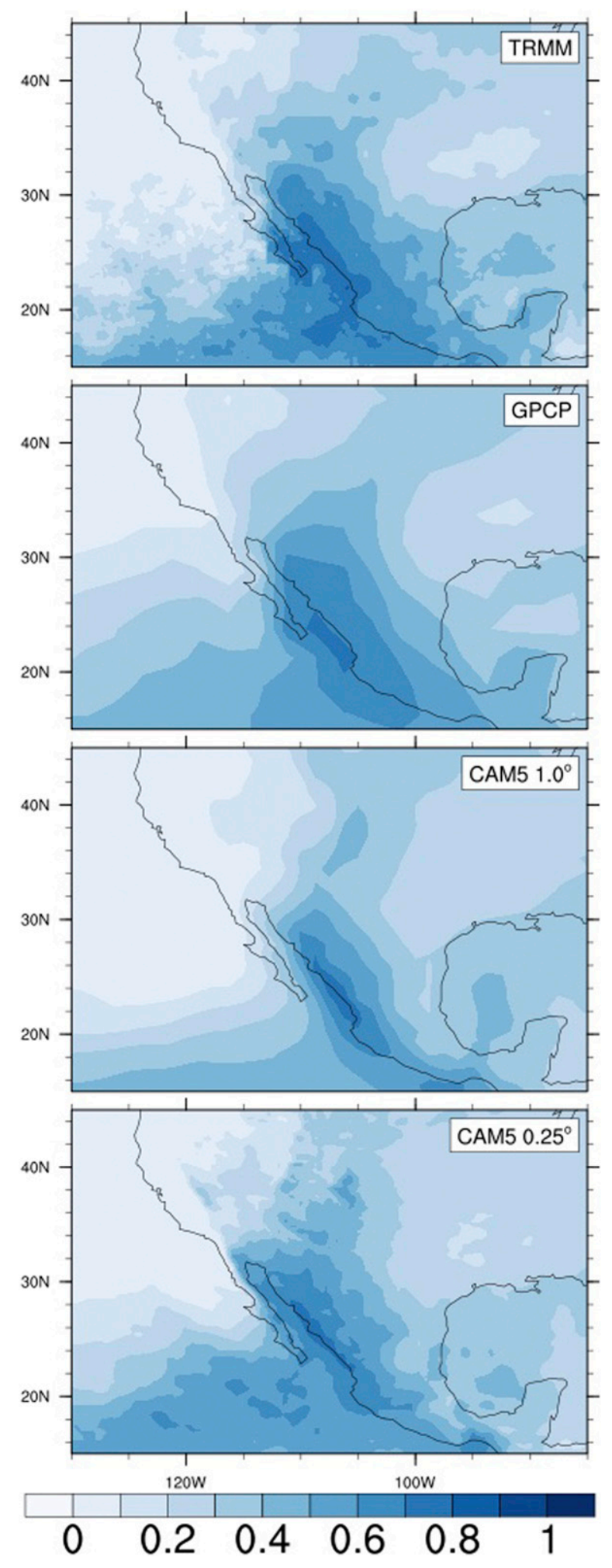

FIG. 5. Monsoon index calculated as the ratio of JAS precipitation to annual precipitation for TRMM, GPCP, CAM5 $1.0^{\circ}$, and CAM5 $0.25^{\circ}$. 
and observations. These results are in line with previous simulations of NAM precipitation in high-resolution regional models (e.g., Cerezo-Mota et al. 2016).

Breaking the precipitation down by regions in Fig. 4, the $0.25^{\circ}$ configuration successfully captures the two observed peaks in precipitation during February and August in the AZNM region not represented in the $1.0^{\circ}$ simulation. However, the magnitude of the AZNM August peak is substantially greater than the observed peak. The high-resolution simulation does not capture the observed dry period in May and June; both the $1.0^{\circ}$ and $0.25^{\circ}$ configurations have reduced precipitation during the spring, but more than is observed. This bias toward too much springtime and fall precipitation and a gradual transition into and out of the monsoon is common in GCMs (Cook and Seager 2013; Geil et al. 2013). The main improvement in the annual cycle of the simulated monsoon over AZNM at the higher-resolution configuration is capturing a more realistic range in precipitation values compared to the $1.0^{\circ}$ simulated monsoon, which has only a subtle annual cycle.

Over the NWM region, the $0.25^{\circ}$ realization of annual cycle of precipitation follows that of the $1.0^{\circ}$ simulation, but again overestimates total rainfall amounts. For the SWM region the double peak in precipitation observations is captured by the $0.25^{\circ}$ CAM5, an improvement over the $1.0^{\circ}$ configuration. However, the first peak in precipitation in the $0.25^{\circ}$ occurs in June, one month earlier than observed in TRMM and GPCP, whereas the second peak does occur in September as observed and is likely directly connected to resolved tropical cyclones. The lull in precipitation in August is the monsoon break that manifests as the midsummer drought across southern Mexico and parts of Central America (e.g., ColoradoRuiz et al. 2018).

Overall, the analysis of precipitation in the NAM region suggests that the increase in resolution from $1.0^{\circ}$ to $0.25^{\circ}$ influences the simulated NAM. In particular, the more realistic simulation of precipitation at $0.25^{\circ}$ in the AZNM region highlights the improvement of the progression and northerly spatial extent of the monsoon at a higher horizontal resolution. The improvement over the $1.0^{\circ}$ model comes from both resolving smaller-scale features and improved representation of topography. The improved later peak in the SWM region is likely dominated by resolving tropical cyclones (Wehner et al. 2014), while the improved northward extension of the NAM into the AZNM region is mainly from the improved representation of the topography on Baja California and therefore of the $\mathrm{GoC}$, which we will show later (see section 5).

The low pressure center, shown in Fig. 3, is larger in magnitude in the $0.25^{\circ}$ simulation, resulting in a stronger pressure gradient compared to the $1.0^{\circ}$ configuration. A stronger pressure gradient results in a more robust shift in the low-level winds (Fig. 3) such that there is southeasterly wind flow through the $\mathrm{GoC}$, more consistent with observations, in the $0.25^{\circ}$ realization, which is not evident in the $1.0^{\circ}$ simulation. In the $1.0^{\circ}$ simulation, the Baja California Peninsula has little or no elevation and most of the $\mathrm{GoC}$ is treated as land rather than ocean in the model (Fig. 1). Therefore there is little ability to channel moisture, explaining why the spatial extent of the monsoon is different between the two simulations. This northward extent of moisture is also seen in the observed MI (Fig. 5), reinforcing the hypothesis that improved topography, specifically improved representation of the Baja California Peninsula and GoC, and surface type in the $0.25^{\circ}$ configuration results in a more realistic simulation of the monsoon. These results support conclusions from previous studies of the impact of topography and the role of horizontal resolution on the development and maintenance of the monsoon that have been investigated in weather models and climate models (both global and regional; Gutzler et al. 2009; Castro et al. 2012; Tripathi and Dominguez 2013; Cook and Seager 2013; Pascale et al. 2017).

\section{Quantifying differences between CAM5 simulations}

Here, we use moist static energy $h$ to better understand how the change in horizontal resolution affects the dynamics of the NAM, with a particular interest in the impact of topography on the monsoon system. As mentioned in section 2c, $h$ is approximately conserved under adiabatic, hydrostatic, and moist transformations, but sources and sinks of $h$ come from diabatic forcing. The climatological patterns of both $h$ and the moist enthalpy $E$ hardly vary from month to month; the predominant pattern is the land-sea contrast with land regions (especially large topographic features) having lower values of both $h$ and $E$.

The formation of precipitation does not alter $h$ directly. Precipitation is weakly related to terms in Eq. (3): thermally forced convection is associated with strong surface fluxes contained within $F^{\text {net }}$ while orographically forced convection is associated with the vertical transport of $h$. These terms are not independent of each other; for example, elevated topography often also has strong surface forcing. Figure 6 shows the terms of Eq. (3) averaged over the JAS season for MERRA-2, $1.0^{\circ}$, and $0.25^{\circ}$ simulations. Along with the terms shown in the equation, we also show the vertical advection of $h$, calculated as $F^{\text {net }}-\langle\overline{\boldsymbol{v} \cdot \nabla E}\rangle$ with monthly averages of 500-hPa omega contours $\left(\omega_{500}\right)$. The residual term, 

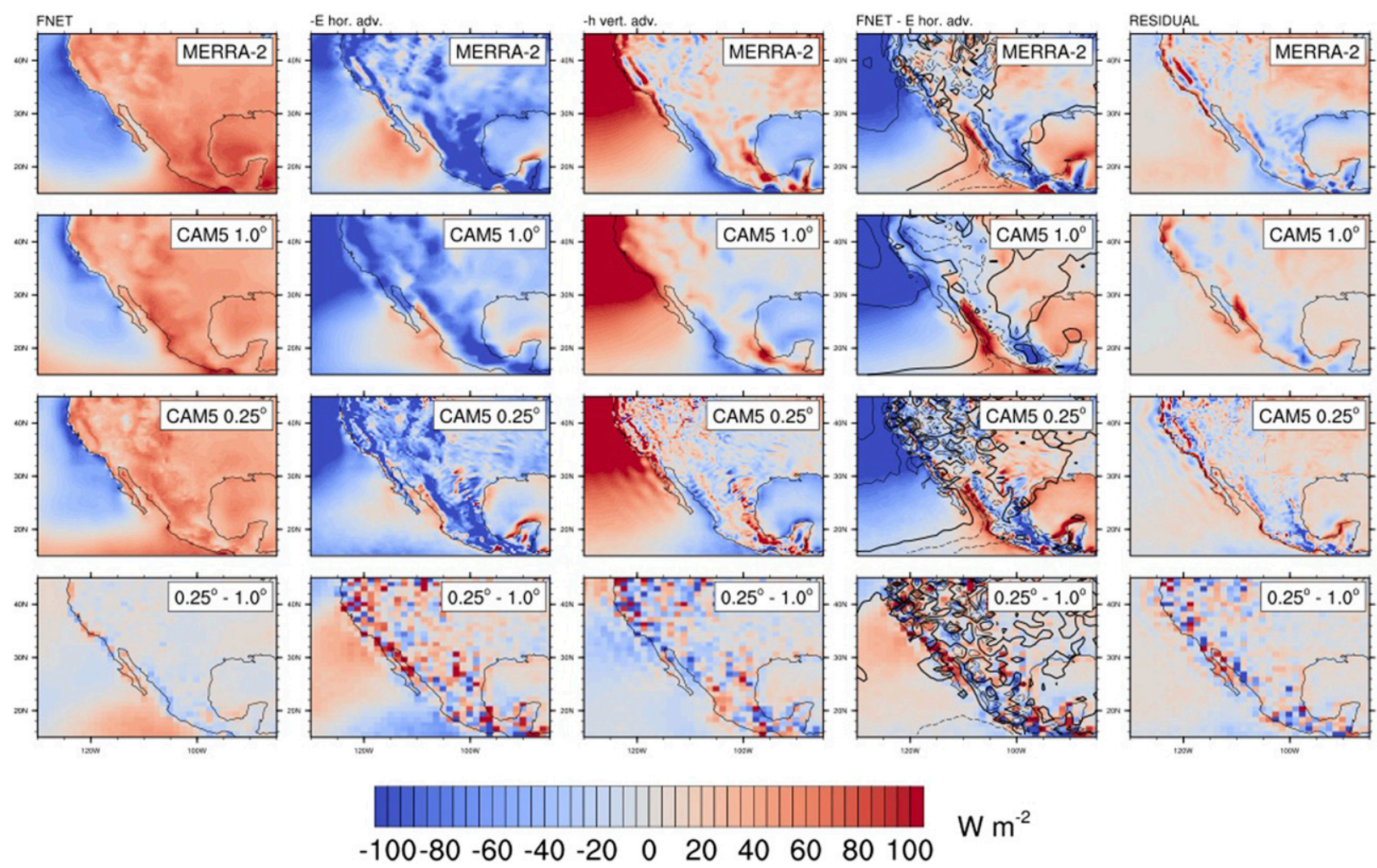

\section{$\mathrm{W} \mathrm{m}^{-2}$}

FIG. 6. Vertically integrated MSE budget averaged over the monsoon season (JAS): (from left to right) net energy flux into the atmospheric column; vertical integral of horizontal advection of $E$; vertical integral of vertical advection of $h ; F^{\text {net }}-\langle v \cdot \nabla E\rangle($ another metric for vertical advection of $h$ ) with 500-hPa vertical pressure velocity $\left(\omega_{500}\right)$ contours; and the residual for MERRA-2, CAM5 1.0 $0^{\circ}$, and CAM5 $0.25^{\circ}$. The $\omega_{500}$ is contoured from -0.06 to 0.06 by $0.03 \mathrm{~Pa} \mathrm{~s}^{-1}$, where the $0 \mathrm{~Pa} \mathrm{~s}^{-1}$ contour is the thick line and the dashed lines indicate upward motion. All of the fields are shown on their native grids except for the differences (bottom panel) and the $\omega_{500}$ contours, which are shown on the CAM5 $1.0^{\circ}$ grid.

calculated by differencing the right-hand side terms from the time derivative of $E$ (calculated using centered differencing), is also shown.

The vertically integrated diabatic forcing $F^{\text {net }}$ shows a strong land-sea contrast in all simulations. As discussed by Neelin (2007), the land surface has low thermal heat capacity, which keeps the surface energy budget relatively close to balanced, so the apparent land-sea contrast is associated with the heat storage by the ocean along with any contrast in top-of-atmosphere radiative forcing. For the most part, the diabatic forcing $F^{\text {net }}$ is balanced by the sum of the dynamic terms. Throughout most of the region, the horizontal advection of moist enthalpy is negative where $F^{\text {net }}$ is positive, indicating that moist enthalpy is being transported away from the positive $F^{\text {net }}$ (Chen and Bordoni 2014). West of the Sierra Madre Occidental Mountains, where NAM precipitation occurs, there is positive horizontal advection of $E$, where $F^{\text {net }}$ is also positive, indicating moist enthalpy is entering the region due to changes in the large-scale circulation (as seen in Fig. 3). In regions of topography, including both the Baja California Peninsula and the Sierra Madre Occidental Mountains, the horizontal and vertical advection terms oppose each other, apparent in MERRA-2 and the $1.0^{\circ}$ simulation. The balance between horizontal and vertical advection is relevant as the westerly-southwesterly flow impacts the Sierra Madre Occidental Mountains, delivering high $h$ (and $E$ ) air to higher elevations and triggering orographic precipitation and thermal convection that redistributes the energy vertically to reduce the column integrated $h$.

Over the GoC, there is also high $E$ and $h$ in both MERRA-2 and the $0.25^{\circ}$ simulation, with lower values in the $1.0^{\circ}$ simulation. We suspect we are capturing some of the transient flow associated with moisture surges that are essential for the northern extension of the NAM (Pascale et al. 2016), but full eddy decomposition analysis is beyond the scope of this work. The fact that there is more advection of $E$ and $h$ occurring in the $0.25^{\circ}$ simulation than in the $1.0^{\circ}$ further solidifies our hypothesis that higher resolution (with more realistic 
topography) results in a large-scale circulation pattern that allows for a more accurate representation of monsoon precipitation. This is apparent in the difference maps for each term between the $0.25^{\circ}$ and $1.0^{\circ}$ simulations in Fig. 6 where there are large differences between the simulations over the northern GoC in both advection terms. A similar analysis of the moisture flux convergence terms following Banacos and Schultz (2005) suggests that the difference in convergence over the northern $\mathrm{GoC}$ is the primary factor for the improvements in the northern extension of the NAM precipitation at higher horizontal resolution (not shown). This improved convergence can be seen in the low-level wind fields (Figs. 3, 7, and 8). This improvement in convergence from the shift in the low-level winds allows for lifting to occur as the $E$ and $h$ meet the topography at the higher resolution.

The vertical advection of $h$, calculated as $F^{\text {net }}-\langle\overline{v \cdot \nabla E}\rangle$, shows that along the coast where the NAM precipitation occurs there is positive vertical advection that is sustained by both the net radiation $F^{\text {net }}$ and horizontal advection $\langle\overline{v \cdot \nabla E}\rangle$. Note that in these panels we are plotting $F^{\text {net }}-\langle\overline{v \cdot \nabla E}\rangle$, not $-\langle\overline{\omega(\partial h / \partial p)}\rangle$, so the signs are opposite such that positive shading corresponds to upward motion. The upward motion along the Sierra Madre Occidental Mountains is highlighted by the dashed $\omega_{500}$ contours. These results are opposite from the analysis done by Chen and Bordoni (2014) in which they were looking at monsoon precipitation occurring over the ocean, where $F^{\text {net }}$ was negative and therefore the monsoon precipitation was sustained just by horizontal advection; we suspect these differences are contingent on the topography of the region.

It should be noted that the residual term is not negligible, as a number of sources of error are present in these calculations. Our definition of $h$ is conventional, but oversimplified; for example, we have ignored the ice phase entirely. The vertical integration, especially of the vertical transport, can be sensitive to interpolation, coarse vertical resolution, and subgrid-scale motions that are unresolved (Neelin 2007; Back and Bretherton 2006; Chen and Bordoni 2014). The residual term appears to reflect a strong imprint of topography, suggestive of these sensitivities to vertical integration and interpolation. It is notable that the residual term shows a close correspondence to the vertical advection of $h$ in the core NAM region for MERRA-2 and both model simulations.

To further assess the moisture budget of the monsoon region, we have assessed enthalpy $E$ and moist static energy $h$ on a specific pressure level $(925 \mathrm{hPa})$ in MERRA-2, CAM5 1.0 $0^{\circ}$ and CAM5 $0.25^{\circ}$ (Figs. 7 and 8).

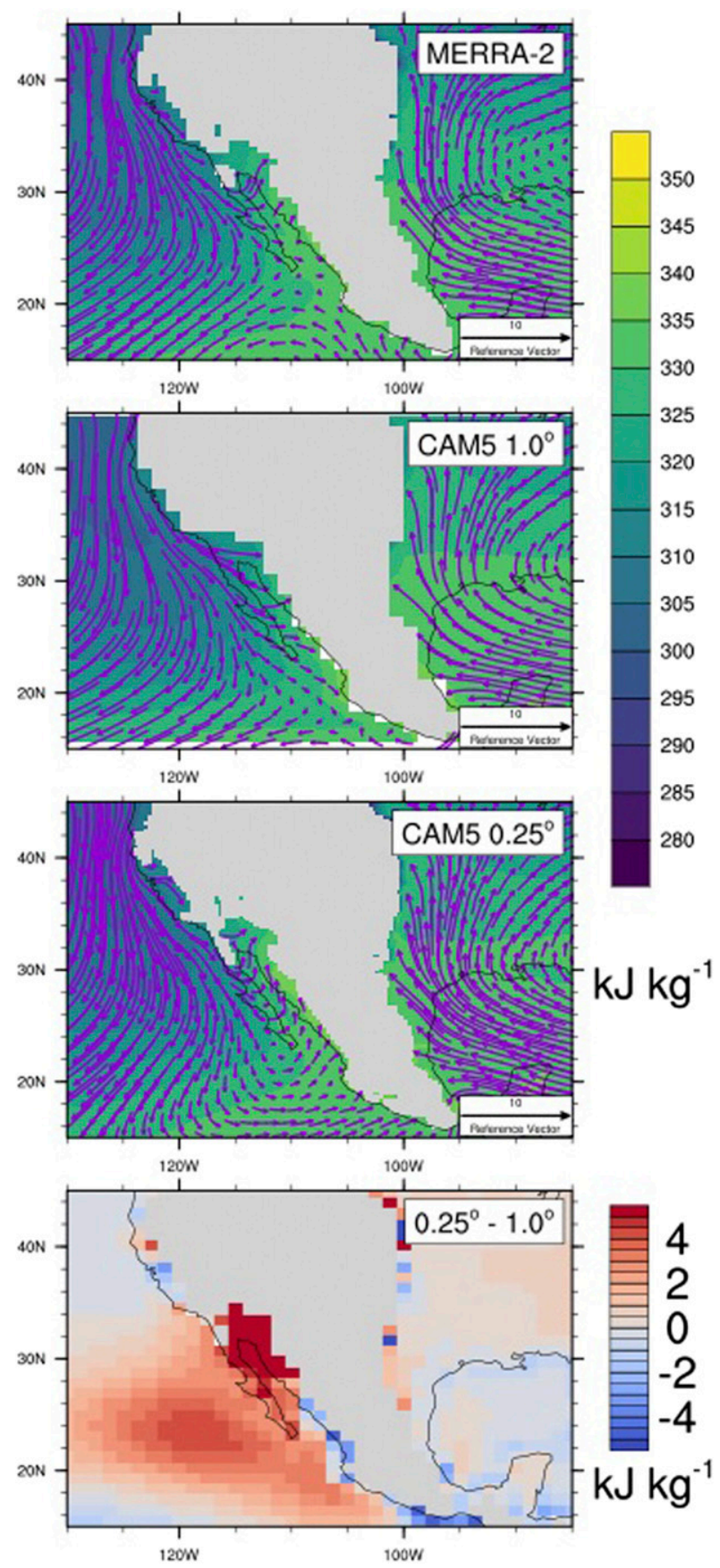

FIG. 7. Enthalpy $E$ at $925 \mathrm{hPa}$ for JAS for MERRA-2, CAM5 $1.0^{\circ}$, and CAM5 $0.25^{\circ}$. Purple vectors represent 925 -hPa winds. The bottom panel is the difference between CAM5 $0.25^{\circ}$ and CAM5 $1.0^{\circ}$. Here $E$ is shown on the native grids but the difference is shown on the CAM5 $1.0^{\circ}$ grid.

We chose $925 \mathrm{hPa}$ as it is has been considered in model analysis of gulf surge events (e.g., Pascale et al. 2016) when 10-m winds are not available and is where we expect topography will have an influence. Note that the climatological patterns of $E$ and $h$ are similar so we only 

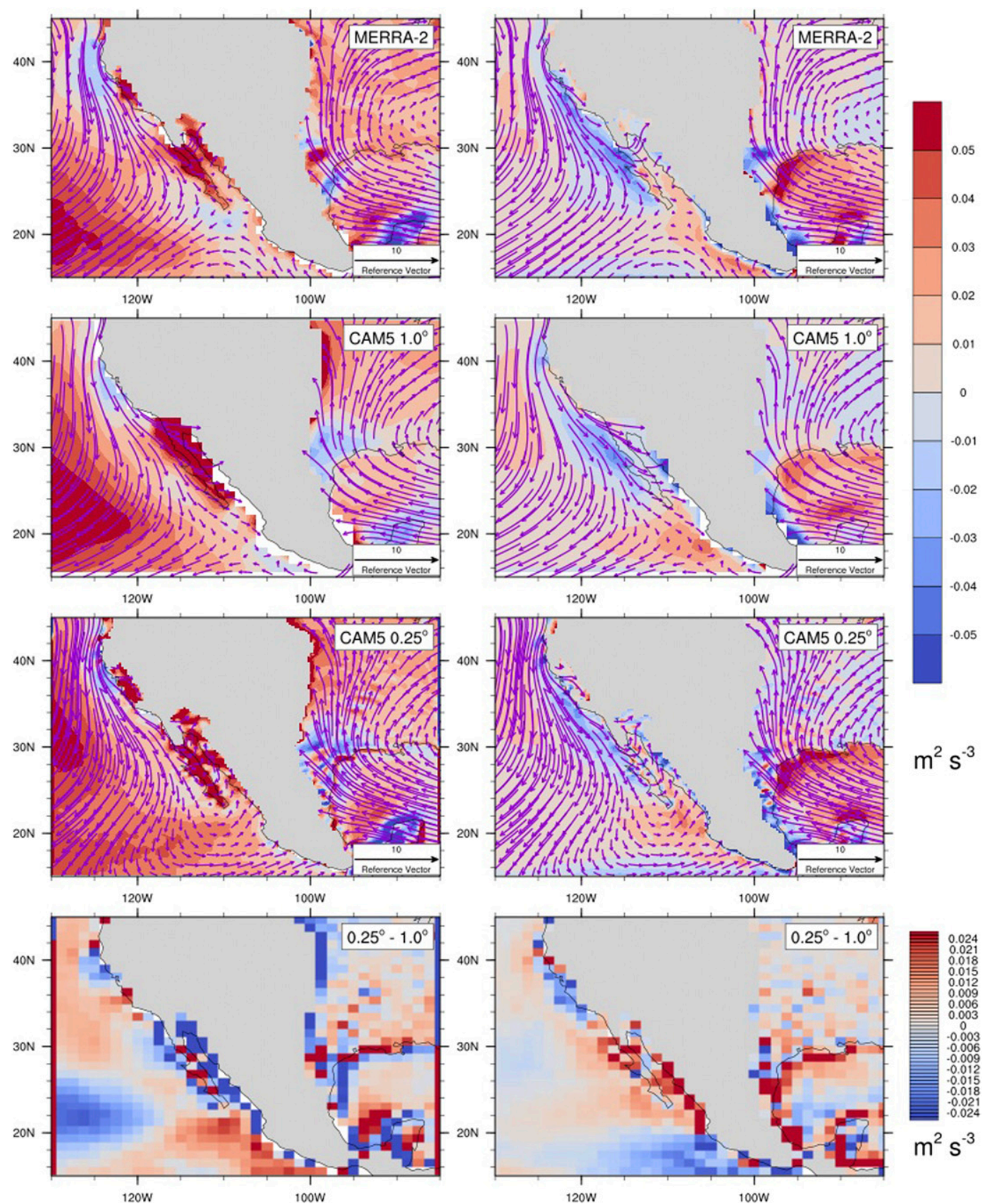

FIG. 8. As in Fig. 7, but showing (left) the horizontal advection of enthalpy $\langle\overline{v \cdot \nabla E}\rangle$ and now including (right) the vertical advection of moist static energy $\overline{\langle\omega(\partial h / \partial p)\rangle} ; E$ and $h$ are shown on the native grids but the differences are shown on the CAM5 $1.0^{\circ}$ grid.

show $E$ in Fig. 7. The difference between CAM5 $0.25^{\circ}$ and CAM5 $1.0^{\circ}$ has also been calculated. At $925 \mathrm{hPa}$, there is a north to south $E$ gradient with higher values of $E$ at the entrance of the GoC than the northern GoC in the reanalysis and model simulations. When comparing the CAM5 $0.25^{\circ}$ configuration to the CAM5 $1.0^{\circ}$ the largest differences between the two simulations are in the northern $\mathrm{GoC}$ where there is more $E$ in the higher- resolution configuration as seen in Fig. 7. When comparing wind vectors between the models, we see that winds are more parallel to the GoC axis at the higher horizontal resolution (Pascale et al. 2018), which is not evident in the $1.0^{\circ}$ configuration. These southerly winds advect $E$ farther north in the GoC, then the topography provides a lift where $E$ is now redistributed vertically as $h$. The regions of positive vertical advection of $h$, 
calculated as $F^{\text {net }}-\langle\overline{v \cdot \nabla E}\rangle$, correspond well with the region of monsoon precipitation (Figs. 3, 5, and 6). Without the southerly flow occurring in the $1.0^{\circ}$ simulation and more smooth topography, there is less $E$ advected into the region, so less $E$ to interact with the topography so there is less lift and less precipitation farther north in the region (as seen in Figs. 3-5).

This can also be investigated through analysis of the $E$ and $h$ advection terms in Eq. (3) on the same 925-hPa pressure level (Fig. 8). In CAM5 $1.0^{\circ}$ the horizontal advection of $E$ is mostly positive through the GoC and of the same magnitude. This indicates that the flow through the $\mathrm{GoC}$ in this simulation is constant throughout the region, as seen by the wind vectors in the plot. However, in MERRA-2 and the CAM5 $0.25^{\circ}$ simulation, there is more variability and structure in the horizontal advection of $E$ throughout the $\mathrm{GoC}$ at this level. This reflects the more southerly wind flow throughout the GoC in both MERRA-2 and CAM5 $0.25^{\circ}$. The vertical advection of $h$ also suggests that there is more vertical transport through the GoC in both MERRA-2 and CAM5 $0.25^{\circ}$, compared to the mostly negative vertical advection of $h$ seen in the $1.0^{\circ}$ simulation. We speculate that the change in wind direction between the $1.0^{\circ}$ and $0.25^{\circ}$ simulation at the low levels, seen in the wind flow and horizontal advection of $E$, drives the increase in vertical transport through the $\mathrm{GoC}$ at the higher horizontal resolution. In comparing seasonal simulations of CAM5 $0.25^{\circ}$, we see similar results between a standard topography simulation and a smoothed topography simulation using the CAM5 $1.0^{\circ}$ topography input (see the appendix). In particular, there is more vertical transport of $h$ in the northern $\mathrm{GoC}$ in the standard topography simulation than in the smoothed topography simulation, likely a result of the change in the horizontal advection of $E$ throughout the GoC; these results point further to the fact that the differences we see in the high-resolution simulation are due to the topographic influence on the low-level flow through the GoC and not simply due to differences related to increased horizontal resolution.

\section{Summary}

This work performs an analysis of the NAM in CAM5 to understand the effect of horizontal resolution and subsequently the orographic effects on the monsoon dynamics. By investigating the simulation of the NAM in CAM5 at the standard horizontal resolution of $1.0^{\circ}$, we found that the model realizes a mean NAM that falls within the observed annual cycle of precipitation, monsoon index (MI), and circulation pattern. However at the $1.0^{\circ}$ horizontal resolution, some of the details of the monsoon are not represented, such as the northern extent of precipitation.
At a higher horizontal resolution $\left(0.25^{\circ}\right)$, CAM5 simulates a monsoon similar to what is realized at $1.0^{\circ}$ but with more detail. In particular the northern extent of the monsoon is better captured at the $0.25^{\circ}$ horizontal resolution, as is the double peak in precipitation in SWM, which we suggest is a result of improved water vapor transport as well as enhanced channeling of moisture up the Gulf of California; this should be further quantified in future work, however. In the $0.25^{\circ}$ simulation, the monsoon low pressure center is stronger than observed, resulting in a more robust shift in winds parallel to the $\mathrm{GoC}$ axis in the $0.25^{\circ}$ simulation. We argue that these changes at higher horizontal resolution in CAM5 are primarily a function of the improved topographic features in the $0.25^{\circ}$ configuration compared to the $1.0^{\circ}$, as the orographic effect on the NAM has been well established (e.g., Gutzler et al. 2009; Castro et al. 2012; Tripathi and Dominguez 2013).

The moisture budget analysis suggests that the northward extension of the NAM captured at $0.25^{\circ}$ horizontal resolution is a result of the better representation of advection of enthalpy and moist static energy over the GoC. This feature is not as well captured in the $1.0^{\circ}$ simulation. Since the $0.25^{\circ}$ simulation conflates improvements from resolving smaller-scale circulation feature and from better representing topography, we conducted a set of short $0.25^{\circ}$ simulations using the $1.0^{\circ}$ topography. These simulations support the notion that improved resolution of the topographic features (especially the Baja California Peninsula) results in a more realistic low-level flow through the $\mathrm{GoC}$ that allows advection of moisture and enthalpy into the NAM region. This improvement in the advection supports the improved northward extension of the NAM. This is seen in the analysis of enthalpy and moist static energy at the 925-hPa pressure level. However, we recognize that making a stronger conclusion about how robust these features are requires decomposing the horizontal advection into transient and stationary eddy components, which is beyond the scope of this work. However, the analysis of the seasonal simulations of CAM5 $0.25^{\circ}$ with standard and smoothed topography (see the appendix) further points to the topography as the primary reason for the improvements seen in the northern extent of NAM precipitation, and that increased resolution is not the only reason for improvements between the $1.0^{\circ}$ and $0.25^{\circ}$ simulations.

This work has shown that the NAM region topography is crucial for the character of the monsoon precipitation (Tang and Reiter 1984; Reiter and Tang 1984; Adams and Comrie 1997; Pascale et al. 2016, 2017) in simulations of CAM5. At the standard $1.0^{\circ}$ grid spacing, the topography is underresolved, and the spatial extent 


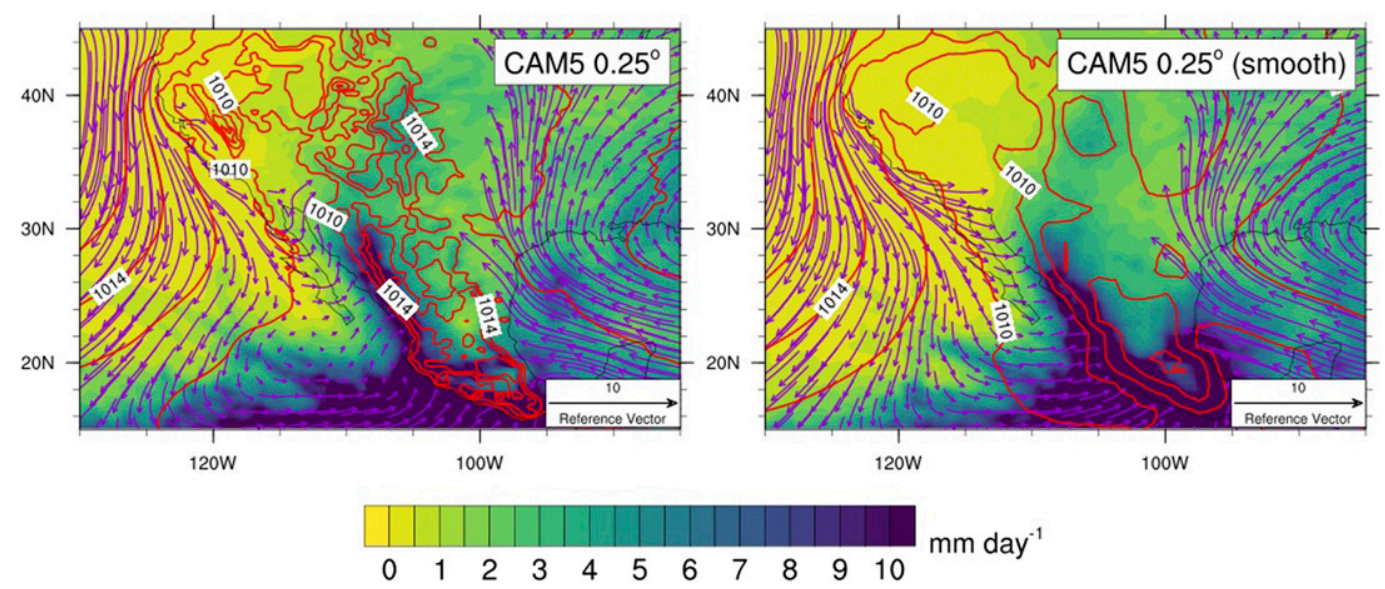

FIG. A1. As in Fig. 3, but for the CAM5 $0.25^{\circ}$ seasonal simulations with the standard topography retained (CAM5 $0.25^{\circ}$ ) and with the smooth CAM5 $1.0^{\circ}$ topography [CAM5 $0.25^{\circ}$ (smooth)].

and timing of the NAM is biased. At high resolution $\left(0.25^{\circ}\right)$ the topographic forcing is much more realistic, and there are improvements in the simulated monsoon's extent and timing. The high-resolution simulation is still imperfect, however, including strongly overestimating the NAM rainfall, and may still be insufficient for understanding the detailed dynamics of the NAM, which
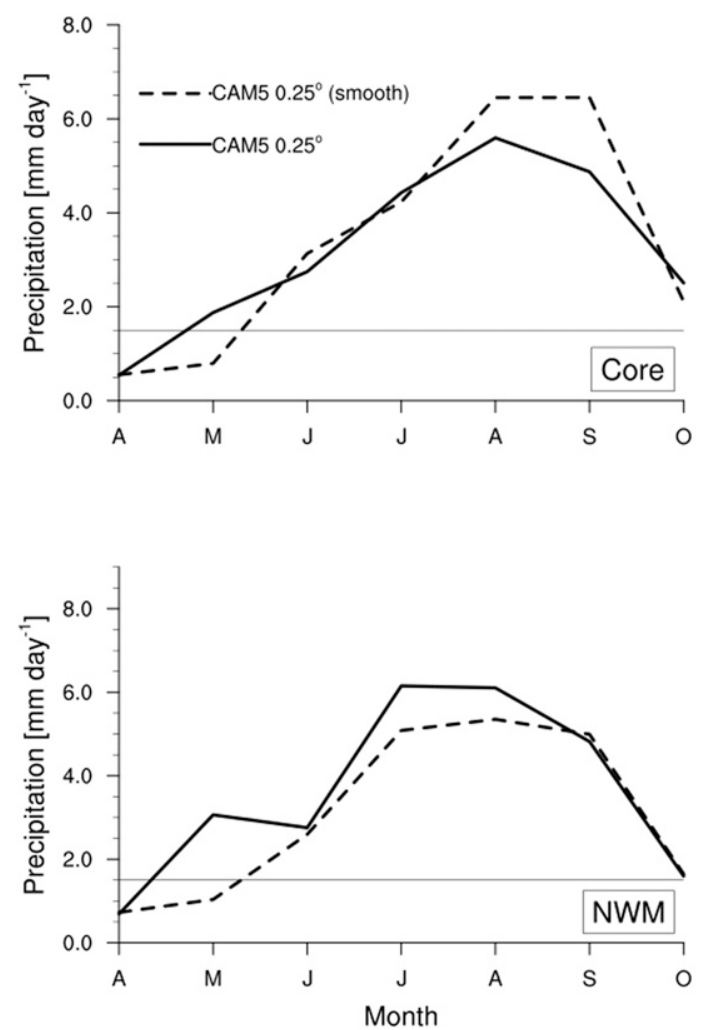

has been the focus of Pascale et al. (2016). This remains a problem of significant societal relevance, as residents of the NAM region depend on monsoon precipitation and accurately projecting the future of the NAM depends on a better understanding of the monsoon circulation in GCMs. High-resolution global climate models are one step toward improving understanding of the climate
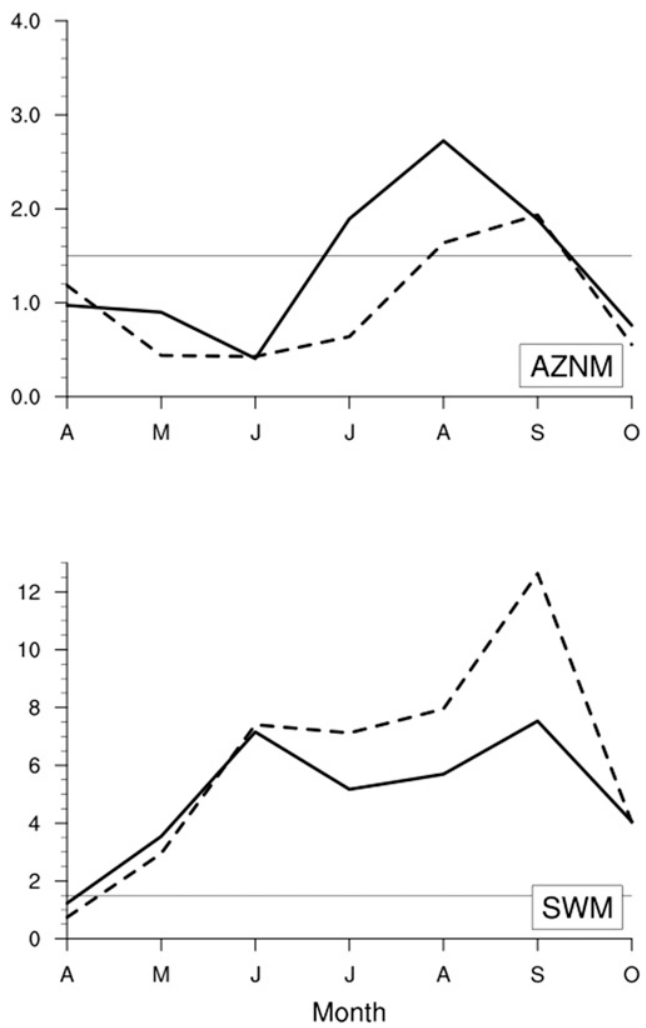

FIG. A2. As in Figs. 2 and 4, but for the CAM5 $0.25^{\circ}$ seasonal simulations with the standard topography retained $\left(\right.$ CAM5 $0.25^{\circ}$ ) and with the smooth CAM5 $1.0^{\circ}$ topography [CAM5 $0.25^{\circ}$ (smooth)] 


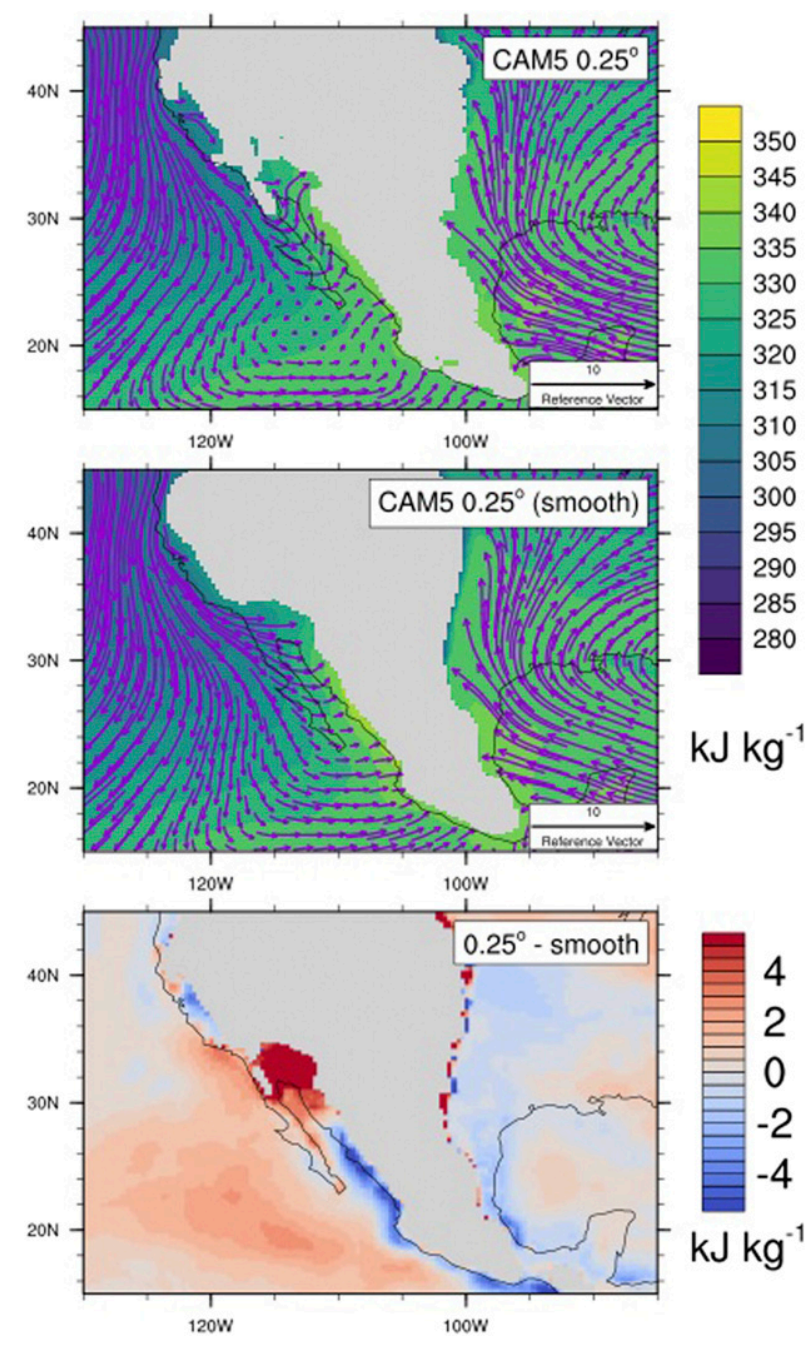

FIG. A3. As in Fig. 7, but for the CAM5 $0.25^{\circ}$ seasonal simulations with the standard topography retained (CAM5 $0.25^{\circ}$ ) and with the smooth CAM5 $1.0^{\circ}$ topography [CAM5 $0.25^{\circ}$ (smooth)].

variability of the NAM. High resolution alone does not guarantee improved simulations, however; detailed analysis and improved physical parameterizations will also be necessary to provide confident projections for the NAM and other large-scale circulation systems.

Acknowledgments. Varuolo-Clarke and Reed were supported by the National Science Foundation under Grant AGS-1648629. Varuolo-Clarke also performed some of this work under the auspices of the Significant Opportunities in Atmospheric Research and Science Program. SOARS is managed by the University Corporation for Atmospheric Research and is funded by the National Science Foundation, the National Center for Atmospheric Research, the National Oceanic and Atmospheric Administration, the Woods Hole Oceano- graphic Institute, the Constellation Observing System for Meteorology, Ionosphere, and Climate and the University of Colorado at Boulder. Portions of this study were supported by the Regional and Global Model Analysis (RGMA) component of the Earth and Environmental System Modeling Program of the U.S. Department of Energy's Office of Biological and Environmental Research (BER) via National Science Foundation IA 1844590. We thank Michael Wehner (Lawrence Berkley National Laboratory) for access to the existing model simulations. We would also like to acknowledge high-performance computing support from NCAR's Computational and Information Systems Laboratory (doi:10.5065/D6RX99HX and ark:/85065/ $\mathrm{d} 7 \mathrm{wd} 3 \mathrm{xhc}$ ). NCAR is sponsored by the National Science Foundation.

\section{APPENDIX}

\section{Seasonal CAM5 $0.25^{\circ}$ Simulations}

To further assess the role of topography on the NAM and its precipitation, additional CAM5 $0.25^{\circ}$ seasonal simulations are performed for April-October for the 2004 season. The 2004 season was chosen so that these simulations could also be used in future work to compare to observational data from the North American Monsoon Experiment (NAME; Higgins and Gochis 2007). The version of CAM5 (i.e., CAM5.3) used for these experiments is a slight update from the version used elsewhere in this project. To assess the impact of the change, we repeated the control experiment for a subinterval of the long control simulation. Comparing the two "control" simulations showed negligible differences in the climate, so we deemed these versions sufficiently similar to conclude that differences with the smooth topography arise from the lower boundary condition, and not from changes in the model's physics. An additional configuration uses this same $0.25^{\circ}$ seasonal configuration but with the topography field taken from the $1.0^{\circ}$ model and interpolated to the $0.25^{\circ}$ grid. For each configuration, three ensemble integrations were performed with small perturbations to the initial atmospheric temperature. The CAM5 configurations used for this study (both AMIP and seasonal) do not include the improvements made to the topography by Lauritzen et al. (2015); those changes have minimal impact on the topographical features discussed here.

Analysis of these simulations provides additional evidence of the important role that topography plays in the simulation of the NAM, particularly the NAM precipitation. With the smoothed topography, precipitation does not extend as far north, the gradient in sea level 

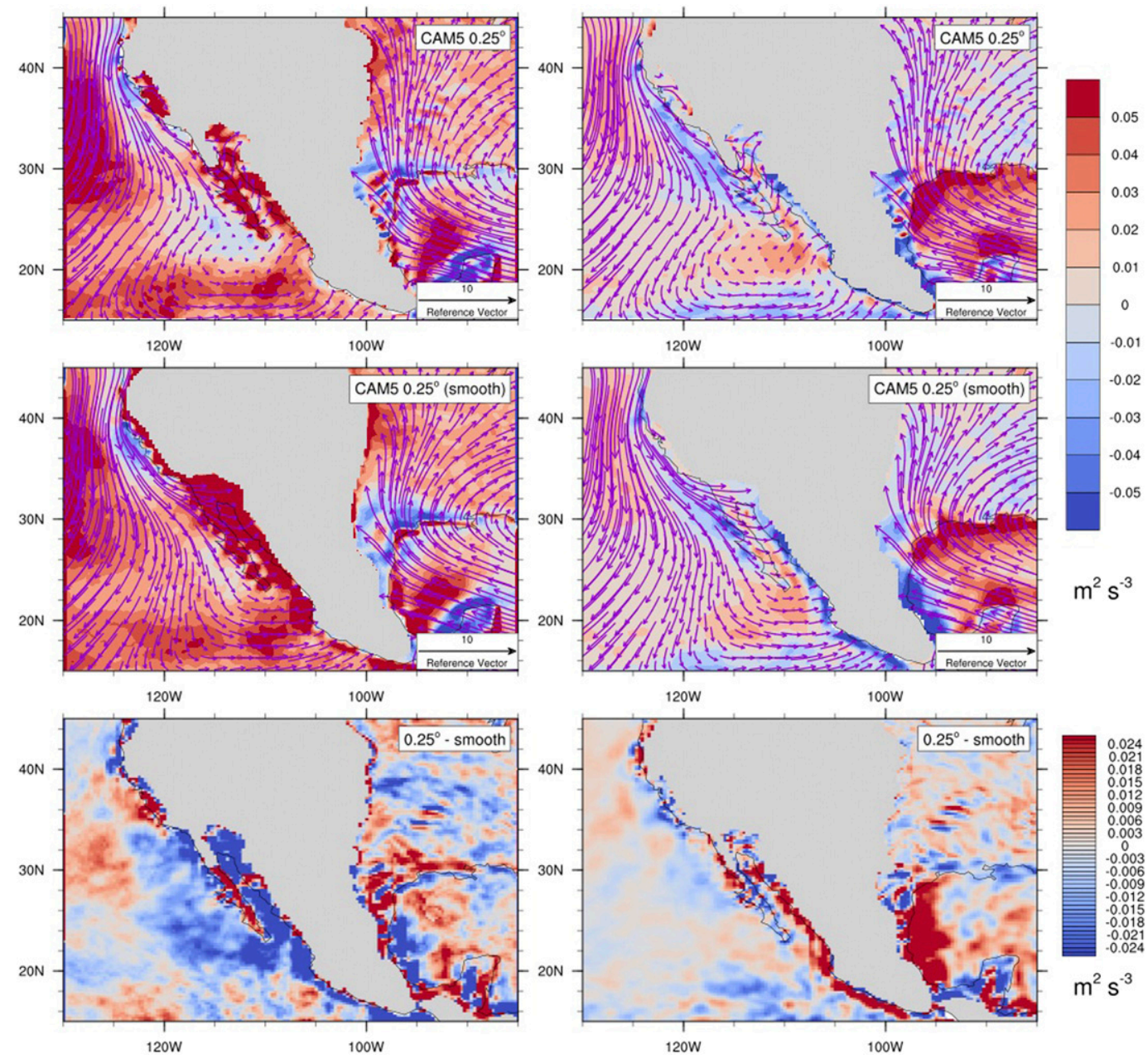

FIG. A4. As in Fig. 8, but for the CAM5 $0.25^{\circ}$ seasonal simulations with the standard topography retained (CAM5 $0.25^{\circ}$ ) and with the smooth CAM5 $1.0^{\circ}$ topography [CAM5 $0.25^{\circ}$ (smooth)].

pressure is weakened compared to the conventional seasonal simulation, and therefore the winds do not flow parallel to the GoC (Fig. A1). The annual average of precipitation over the core monsoon region is greater in the smoothed topography simulation than in the standard topography simulation (Fig. A2). Breaking the precipitation down by regions in Fig. A2, as done for full AMIP simulations, the smoothed topography simulation underestimates precipitation in the AZNM region while simulating too much rain in the SWM region when compared to the full topography simulation. This is similar to what is seen in the regional analysis of the CAM5 $1.0^{\circ}$ simulation (Fig. 4). This highlights the fact that improvements in NAM precipitation between the CAM5 $1.0^{\circ}$ and CAM5 $0.25^{\circ}$ simulation are due to more than just the increased horizontal resolution, but we argue it is due to the improved topography that is a result of the increased horizontal resolution.
When investigating the enthalpy $E$ and moist static energy $h$ at $925 \mathrm{hPa}$, the standard topography simulation simulates more $E$ (and $h$ ) at the northern GoC than in the smoothed topography simulation. This is evident in the difference maps in Fig. A3. The authors speculate that the reason for more energy in the northern GoC in the standard topography simulation is a result of more productive $E$ advection occurring through the GoC as a result of the more southerly winds that promote convergence through the gulf leading to a buildup of $E$. Then this increase in $E$ is advected vertically in the northern $\mathrm{GoC}$ as $h$ (Fig. A4), contributing to the precipitation the region experiences (Fig. A1). We find these simulations and the subsequent analysis to be useful in further solidifying our hypothesis that the improved northern extent of NAM precipitation at higher resolution is influenced by the more realistic topography. Further, 
this analysis sets the framework for future work to further disentangle the influence of large-scale circulation and topography on the North American monsoon.

\section{REFERENCES}

Adams, D. K., and A. C. Comrie, 1997: The North American monsoon. Bull. Amer. Meteor. Soc., 78, 2197-2213, https://doi.org/ 10.1175/1520-0477(1997)078<2197:TNAM >2.0.CO;2.

Adams, J. L., and D. J. Stensrud, 2007: Impact of tropical easterly waves on the North American monsoon. J. Climate, 20, 12191238, https://doi.org/10.1175/JCLI4071.1.

Adler, R., and Coauthors, 2018: The Global Precipitation Climatology Project (GPCP) monthly analysis (new version 2.3) and a review of 2017 global precipitation. Atmosphere, 9, 138, https://doi.org/10.3390/atmos9040138.

Anderson, B. T., and J. O. Roads, 2001: Summertime moisture divergence over the southwestern US and northwestern Mexico. Geophys. Res. Lett., 28, 1973-1976, https://doi.org/ 10.1029/2001GL012903.

Back, L. E., and C. S. Bretherton, 2006: Geographic variability in the export of moist static energy and vertical motion profiles in the tropical Pacific. Geophys. Res. Lett., 33, L17810, https:// doi.org/10.1029/2006GL026672.

Bacmeister, J. T., M. F. Wehner, R. B. Neale, A. Gettelman, C. Hannay, P. H. Lauritzen, J. M. Caron, and J. E. Truesdale, 2014: Exploratory high-resolution climate simulations using the Community Atmosphere Model (CAM). J. Climate, 27, 3073-3099, https://doi.org/10.1175/JCLI-D-13-00387.1.

Banacos, P. C., and D. M. Schultz, 2005: The use of moisture flux convergence in forecasting convective initiation: Historical and operational perspectives. Wea. Forecasting, 20, 351-366, https://doi.org/10.1175/WAF858.1.

Bryson, R. A., and W. P. Lowry, 1955: Synoptic climatology of the Arizona summer precipitation singularity. Bull. Amer. Meteor. Soc., 36, 329-339, https://doi.org/10.1175/1520-0477-36.7.329.

Carleton, A. M., 1986: Synoptic-dynamic character of 'bursts' and 'breaks' in the South-West U.S. summer precipitation singularity. Int. J. Climatol., 6, 605-623, https://doi.org/10.1002/ joc.3370060604.

_ 1987: Summer circulation climate of the American Southwest: 1945-1984. Ann. Assoc. Amer. Geogr., 77, 619-634, https://doi.org/10.1111/j.1467-8306.1987.tb00184.x.

Castro, C. L., H.-I. Chang, F. Dominguez, C. Carrillo, J.-K. Schemm, and H.-M. Henry Juang, 2012: Can a regional climate model improve the ability to forecast the North American monsoon? J. Climate, 25, 8212-8237, https://doi.org/ 10.1175/JCLI-D-11-00441.1.

Cerezo-Mota, R., T. Cavazos, R. Arritt, A. Torres-Alavez, K. Sieck, G. Nikulin, W. Moufouma-Okia, and J. A. SalinasPrieto, 2016: CORDEX-NA: Factors inducing dry/wet years on the North American monsoon region. Int. J. Climatol., 36, 824-836, https://doi.org/10.1002/joc.4385.

Chen, J., and S. Bordoni, 2014: Orographic effects of the Tibetan Plateau on the East Asian summer monsoon: An energetic perspective. J. Climate, 27, 3052-3072, https://doi.org/10.1175/ JCLI-D-13-00479.1.

Chou, C., and J. D. Neelin, 2003: Mechanisms limiting the northward extent of the northern summer monsoons over North America, Asia, and Africa. J. Climate, 16, 406-425, https://doi.org/10.1175/ 1520-0442(2003)016<0406:MLTNEO>2.0.CO;2.
Colorado-Ruiz, G., T. Cavazos, J. A. Salinas, P. De Grau, and R. Ayala, 2018: Climate change projections from Coupled Model Intercomparison Project phase 5 multi-model weighted ensembles for Mexico, the North American monsoon, and the mid-summer drought region. Int. J. Climatol., 38, 5699-5716, https://doi.org/10.1002/joc.5773.

Cook, B. I., and R. Seager, 2013: The response of the North American monsoon to increased greenhouse gas forcing. J. Geophys. Res. Atmos., 118, 1690-1699, https://doi.org/ 10.1002/jgrd.50111.

Dominguez, F., G. Miguez-Macho, and H. Hu, 2016: WRF with water vapor tracers: A study of moisture sources for the North American monsoon. J. Hydrometeor., 17, 1915-1927, https:// doi.org/10.1175/JHM-D-15-0221.1.

Douglas, M. W., 1995: The summertime low-level jet over the Gulf of California. Mon. Wea. Rev., 123, 2334-2347, https://doi.org/ 10.1175/1520-0493(1995)123<2334:TSLLJO > 2.0.CO;2.

Finch, Z. O., and R. H. Johnson, 2010: Observational analysis of an upper-level inverted trough during the 2004 North American Monsoon Experiment. Mon. Wea. Rev., 138, 3540-3555, https://doi.org/10.1175/2010MWR3369.1.

Gates, W. L., and Coauthors, 1999: An overview of the results of the Atmospheric Model Intercomparison Project (AMIP I). Bull. Amer. Meteor. Soc., 80, 29-56, https://doi.org/10.1175/ 1520-0477(1999)080<0029:AOOTRO > 2.0.CO;2.

Geil, K. L., Y. L. Serra, and X. Zeng, 2013: Assessment of CMIP5 model simulations of the North American monsoon system. J. Climate, 26, 8787-8801, https://doi.org/10.1175/JCLI-D-1300044.1.

Gelaro, R., and Coauthors, 2017: The Modern-Era Retrospective Analysis for Research and Applications, version 2 (MERRA-2). J. Climate, 30, 5419-5454, https://doi.org/10.1175/JCLI-D-160758.1.

Global Modeling and Assimilation Office, 2015a: M2I3NPASM: MERRA-2 inst3 3d asm Np: 3d, 3-Hourly, Instantaneous, Pressure-level, Assimilation, Assimilated meteorological fields v5.12.4. Goddard Earth Sciences Data and Information Services Center (GES DISC), accessed October 2017, https:// doi.org/10.5067/QBZ6MG944HW0. 2015b: M2IMNXASM: MERRA-2 instm 2d asm Nx: 2d, Monthly mean, Single-level, Assimilation, Single-level diagnostics v5.12.4. Goddard Earth Sciences Data and Information Services Center (GES DISC), accessed October 2017, https://doi.org/10.5067/5ESKGQTZG7FO.

2015c: M2T1NXFLX: MERRA-2 tavg1 2d flx Nx: 2d, 1-Hourly, Time-Averaged, Single-Level, Assimilation, Surface Flux Diagnostics V5.12.4. Data retrieved from Goddard Earth Sciences Data and Information Services Center (GES DISC), accessed October 2017, https://doi.org/10.5067/7MCPBJ41Y0K6.

- 2015d: M2T1NXRAD: MERRA-2 tavg1 2d rad Nx: 2d, 1-Hourly, Time-Averaged, Single-Level, Assimilation, Radiation Diagnostics v5.12.4. Data retrieved from Goddard Earth Sciences Data and Information Services Center (GES DISC), accessed October 2017, https://doi.org/10.5067/Q9QMY5PBNV1T.

Gutzler, D. S., and Coauthors, 2009: Simulations of the 2004 North American monsoon: NAMAP2. J. Climate, 22, 6716-6740, https://doi.org/10.1175/2009JCLI3138.1.

Higgins, R. W., Y. Chen, and A. V. Douglas, 1999: Interannual variability of the North American warm season precipitation regime. J. Climate, 12, 653-680, https://doi.org/10.1175/15200442(1999)012<0653:IVOTNA > 2.0.CO;2.

Higgins, W., and D. Gochis, 2007: Synthesis of results from the North American Monsoon Experiment (NAME) process 
study. J. Climate, 20, 1601-1607, https://doi.org/10.1175/ JCLI4081.1.

Huffman, G. J., R. F. Adler, D. T. Bolvin, and G. Gu, 2009: Improving the global precipitation record: GPCP version 2.1. Geophys. Res. Lett., 36, L17808, https://doi.org/10.1029/ 2009GL040000.

Kim, H.-J., B. Wang, and Q. Ding, 2008: The global monsoon variability simulated by CMIP3 coupled climate models. J. Climate, 21, 5271-5294, https://doi.org/10.1175/2008JCLI2041.1.

Kummerow, C., W. Barnes, T. Kozu, J. Shiue, and J. Simpson, 1998: The Tropical Rainfall Measuring Mission (TRMM) sensor package. J. Atmos. Oceanic Technol., 15, 809-817, https://doi.org/ 10.1175/1520-0426(1998)015<0809:TTRMMT>2.0.CO;2.

Lauritzen, P. H., J. T. Bacmeister, P. F. Callaghan, and M. A. Taylor, 2015: NCAR_Topo (v1.0): NCAR global model topography generation software for unstructured grids. Geosci. Model Dev., 8, 3975-3986, https://doi.org/10.5194/gmd-8-3975-2015.

Martinez-Sanchez, J. N., and T. Cavazos, 2014: Eastern tropical Pacific hurricane variability and landfalls on Mexican coasts. Climate Res., 58, 221-234, https://doi.org/10.3354/cr01192.

Neale, R. B., and Coauthors, 2012: Description of the NCAR Community Atmosphere Model (CAM 5.0). NCAR Tech. Note NCAR/TN-486+STR, 274 pp., www.cesm.ucar.edu/ models/cesm1.0/cam/docs/description/cam5_desc.pdf.

Neelin, J. D., 2007: Moist dynamics of tropical convection zones in monsoons, teleconnections and global warming. The Global Circulation of the Atmosphere, T. Schneider and A. Sobel, Eds., Princeton University Press, 267-301.

Newman, A. J., and R. H. Johnson, 2012: Simulation of a North American monsoon Gulf surge event and comparison to observations. Mon. Wea. Rev., 140, 2534-2554, https://doi.org/ 10.1175/MWR-D-11-00223.1.

_, and - 2013: Dynamics of a simulated North American monsoon Gulf surge event. Mon. Wea. Rev., 141, 3238-3253, https://doi.org/10.1175/MWR-D-12-00294.1.

Pascale, S., S. Bordoni, S. B. Kapnick, G. A. Vecchi, L. Jia, T. L. Delworth, S. Underwood, and W. Anderson, 2016: The impact of horizontal resolution on North American monsoon Gulf of California moisture surges in a suite of coupled global climate models. J. Climate, 29, 7911-7936, https://doi.org/10.1175/ JCLI-D-16-0199.1.

, W. R. Boos, S. Bordoni, T. L. Delworth, S. B. Kapnick, H. Murakami, G. A. Vecchi, and W. Zhang, 2017: Weakening of the North American monsoon with global warming. Nat. Climate Change, 7, 806-812, https://doi.org/10.1038/ nclimate3412.

— S. B. Kapnick, S. Bordoni, and T. L. Delworth, 2018: The influence of $\mathrm{CO}_{2}$ forcing on North American monsoon moisture surges. J. Climate, 31, 7949-7968, https://doi.org/10.1175/ JCLI-D-18-0007.1.

Rasmusson, E. M., 1967: Atmospheric water vapor transport and the water balance of North America: Part I. Characteristics of the water vapor flux field. Mon. Wea. Rev., 95, 403-426, https://doi.org/ 10.1175/1520-0493(1967)095<0403:AWVTAT>2.3.CO;2.

Reed, T. R., 1933: The North American high-level anticyclone. Mon. Wea. Rev., 61, 321-325, https://doi.org/10.1175/15200493(1933)61<321:TNAHA $>2.0$.CO;2.

Reitan, C. H., 1957: The role of precipitable water vapor in Arizona's summer rains. Tech. Rep. on the Meteorology and Climatology of Arid Regions, No. 2, The Institute of Atmospheric Physics, The University of Arizona, $19 \mathrm{pp}$.

Reiter, E. R., and M. Tang, 1984: Plateau effects on diurnal circulation patterns. Mon. Wea. Rev., 112, 638-651, https://doi.org/ 10.1175/1520-0493(1984)112<0638:PEODCP > 2.0.CO;2.

Richter, J. H., A. Solomon, and J. T. Bacmeister, 2014: On the simulation of the quasi-biennial oscillation in the Community Atmosphere Model, version 5. J. Geophys. Res., 119, 30453062, https://doi.org/10.1002/2013JD021122.

Ritchie, E. A., K. M. Wood, D. S. Gutzler, and S. R. White, 2011 The influence of eastern Pacific tropical cyclone remnants on the southwestern United States. Mon. Wea. Rev., 139, 192210, https://doi.org/10.1175/2010MWR3389.1.

Schmitz, J. T., and S. L. Mullen, 1996: Water vapor transport associated with the summertime North American monsoon as depicted by ECMWF analyses. J. Climate, 9, 1621-1634, https://doi.org/ 10.1175/1520-0442(1996)009<1621:WVTAWT>2.0.CO;2.

Seastrand, S., Y. Serra, C. Castro, and E. Ritchie, 2015: The dominant synoptic-scale modes of North American monsoon precipitation. Int. J. Climatol., 35, 2019-2032, https://doi.org/ 10.1002/joc.4104.

Tang, M., and E. R. Reiter, 1984: Plateau monsoons of the Northern Hemisphere: A comparison between North America and Tibet. Mon. Wea. Rev., 112, 617-637, https://doi.org/ 10.1175/1520-0493(1984)112<0617:PMOTNH>2.0.CO;2.

Trenberth, K. E., D. P. Stepaniak, and J. M. Caron, 2000: The global monsoon as seen through the divergent atmospheric circulation. J. Climate, 13, 3969-3993, https://doi.org/10.1175/ 1520-0442(2000)013<3969:TGMAST > 2.0.CO;2.

Tripathi, O. P., and F. Dominguez, 2013: Effects of spatial resolution in the simulation of daily and subdaily precipitation in the southwestern US. J. Geophys. Res. Atmos., 118, 75917605, https://doi.org/10.1002/JGRD.50590.

Turrent, C., and T. Cavazos, 2009: Role of the land-sea thermal contrast in the interannual modulation of the North American Monsoon. Geophys. Res. Lett., 36, L02808, https://doi.org/ 10.1029/2008GL036299.

Wehner, M. F., and Coauthors, 2014: The effect of horizontal resolution on simulation quality in the Community Atmospheric Model, CAM5.1. J. Adv. Model. Earth Syst., 6, 980997, https://doi.org/10.1002/2013MS000276.

Yano, J.-I., and M. H. P. Ambaum, 2017: Moist static energy: Definition, reference constants, a conservation law and effects on buoyancy. Quart. J. Roy. Meteor. Soc., 143, 2727-2734, https://doi.org/10.1002/qj.3121. 